\title{
Estrategias alternativas para el diagnóstico de tuberculosis: una opción para los pacientes paucibacilares
}

\author{
Alternative strategies for the tuberculosis diagnosis: \\ An option for paucibacillary patients
}

\section{Sergio F. Mosquera-Restrepo PhD', Marta C. Mesa-Villanueva PhD', Mauricio Rojas-López $P h D^{3}$}

Resumen: el diagnóstico de la tuberculosis ha estado basado en la detección directa de la micobacteria; sin embargo, se estima que este se puede lograr solamente en el $10 \%$ de los casos y requiere que se combine con métodos confirmatorios como el cultivo, el cual puede tomar varias semanas para que el crecimiento sea evidente. Los métodos basados en la amplificación de la secuencia ácidos nucleicos muestran sensibilidad y especificidad altas, pero no siempre son accesibles a todos los laboratorios debido a sus requerimientos de infraestructura y el costo de los insumos. Las limitaciones para el diagnóstico hacen que se busque continuamente metabolitos micobacterianos, mediante diferentes aproximaciones, que sean, ulteriormente, fáciles de rastrear en condiciones muy básicas de laboratorio. En esta revisión se incluyen algunas de las aproximaciones metodológicas basadas en la detección de derivados micobacterianos y su valor como herramienta para el rastreo de la micobacteria.

Palabras clave: tuberculosis, lípidos, lipoarabinomanano, dimicolato de trehalosa, cromatografía.

Mosquera-Restrepo SF, Mesa-Villanueva MC, Rojas-López M. Estrategias alternativas para el diagnóstico de tuberculosis: una opción para los pacientes paucibacilares. Medicina \& Laboratorio 2017; 23: 513-550.

\footnotetext{
${ }^{1}$ Bacteriólogo, MSc y PhD en Ciencias Básicas Biomédicas. Docente, Facultad de Medicina Veterinaria y Zootecnia, Fundación Universitaria Autónoma de las Américas. Medellín, Colombia.

${ }^{2}$ Bacterióloga, MSc en Microbiología, PhD en Ciencias Biológicas. Exprofesora del Departamento de Microbiología, Pontificia Universidad Javeriana. Bogotá, Colombia.

${ }^{3}$ Biólogo, MSc en Inmunología, PhD en Ciencias (Inmunología). Profesor e investigador, Grupo de Inmunología Celular e Inmunogenética, Facultad de Medicina, Universidad de Antioquia. Coordinador Unidad de Citometría de Flujo, Sede de Investigación Universitaria, Universidad de Antioquia. Medellin, Colombia. Correspondencia: Calle 70 N. ${ }^{\circ}$ 52-21. Correo electrónico: mauricio.rojas@udea.edu.co
} 
$\int \begin{aligned} & \text { ycobacterium tuberculosis es el } \\ & \text { agente etiológico de la tuberculo- }\end{aligned}$ sis, enfermedad que afecta principalmente el sistema respiratorio del hospedero. Este microorganismo se transmite a través de aerosoles desde un paciente bacilífero a otros individuos. Según la Organización Mundial de la Salud (OMS) la tuberculosis es la novena causa mundial de muerte y la primera debido a enfermedades infecciosas, por encima del VIH/SIDA. En 2016 la cifra estimada de muertes por tuberculosis fue de 1.300 .000 (frente a los 1.700 .000 en 2000) en personas VIH negativas y de 374.000 en personas VIH positivas [1].

En Colombia, según el reporte de la OMS, en el año 2016 hubo una incidencia total de tuberculosis de 16 por cada 100.000 habitantes. En este mismo año se notificó un total de 13.467 casos, de los cuales solo el 9\% tuvieron un diagnóstico con una prueba rápida y el $80 \%$ alcanzaron a tener la confirmación bacteriológica ulterior mediante cultivo. En este mismo reporte de la OMS se evidencia una reducción en el presupuesto para la financiación de los programas para la prevención, el diagnóstico y el tratamiento de la tuberculosis en Colombia para el 2017, con un notorio incremento en el déficit financiero total y una marcada disminución en la financiación externa [2], lo que inevitablemente se convierte en un factor apremiante para la búsqueda local de estrategias que den soluciones al problema del diagnóstico temprano de la tuberculosis.

Según la OMS una tercera parte de la población mundial está infectada con Mycobacterium tuberculosis [1]. Después de la infección primaria un porcentaje bajo de individuos puede desarrollar tuberculosis activa, mientras que un $90 \%$ al $95 \%$ perma- nece asintomático, con una forma de la enfermedad denominada tuberculosis latente [3]. A esto se suma la tuberculosis farmacorresistente, que continúa siendo una amenaza. Específicamente, en 2016 hubo en el mundo 600.000 nuevos casos resistentes a la rifampicina, el fármaco de primera línea más eficaz, 490.000 de los cuales tenían tuberculosis multirresistente. Cerca de la mitad (47\%) de estos casos se produjeron en India, China y la Federación de Rusia [1]. Este panorama, que toma cifras a nivel local y mundial, hace evidente que, si bien algunos indicadores pueden mostrar reducción de la enfermedad, el problema ha ganado complejidad en diferentes frentes.

De esta manera, la tuberculosis se ha mantenido a través de los años como uno de los problemas más importantes de salud pública, que presenta dificultades importantes para su control, principalmente la falta de un diagnóstico confiable y oportuno de las formas pulmonares y extrapulmonares que permita iniciar a tiempo el tratamiento y disminuir la transmisión. En esta revisión se describen las herramientas diagnósticas convencionales utilizadas en la detección de las formas activas de la enfermedad, sus ventajas y desventajas, así como su aplicación en el diagnóstico de individuos paucibacilares y de individuos con infección latente. Además, se describen algunos componentes y derivados de la micobacteria de naturaleza lipídica, como el manósido de fosfatidil inositol (PIM), el lipoarabinomanano (LAM), el dimicolato de trehalosa (TDM) y algunos ácidos grasos como el ácido tuberculoestárico (TBSA) y los ácidos micólicos, que se han postulado que son útiles para la detección del microorganismo. Finalmente, se describen algunos métodos para su detección en muestras clínicas. 


\section{Diagnóstico de la infección tuberculosa latente con base en la respuesta inmune}

La mayoría de las personas infectadas por Mycobacterium tuberculosis no presentan signos ni síntomas de la enfermedad, pero corren el riesgo de contraer la forma activa. Se estima que la infección tuberculosa latente progresa a enfermedad activa en el $5 \%$ al $10 \%$ de las personas infectadas, y que esta progresión es más grande en individuos inmunocomprometidos. En la mayoría de los casos se contrae la tuberculosis activa en los primeros cinco años, luego de la infección inicial [3]. En los países desarrollados los individuos con infección tuberculosa latente, y aquellos con alto riesgo de desarrollarla, reciben terapia profiláctica [1], ya que son considerados reservorios de la micobacteria. De esta manera, la implementación de métodos de alta sensibilidad y especificidad para la detección de la micobacteria se considera prioritaria. Las principales técnicas para el diagnóstico de la infección tuberculosa latente, basada en la respuesta inmune, se describen a continuación.

\section{Prueba de tuberculina en piel}

La tuberculina es una suspensión en glicerol de derivado proteico purificado (PPD), que es un precipitado de antígenos no específicos obtenido a partir del filtrado del cultivo de Mycobacterium tuberculosis [4]. La aplicación de la prueba de tuberculina fue iniciada por Robert Koch a finales del siglo XIX, cuando observó que, después de inocular el PPD por vía subcutánea, se producía una reacción febril en los pacientes con tuberculosis pero no en los individuos sin la enfermedad; razón por la que se empezó a utilizar como una herramienta diagnóstica. Después, la inoculación subcutánea se cambió a inoculación intradérmica para restringir la reacción a la piel (prueba de Mantoux) (véase figura 1) [3].

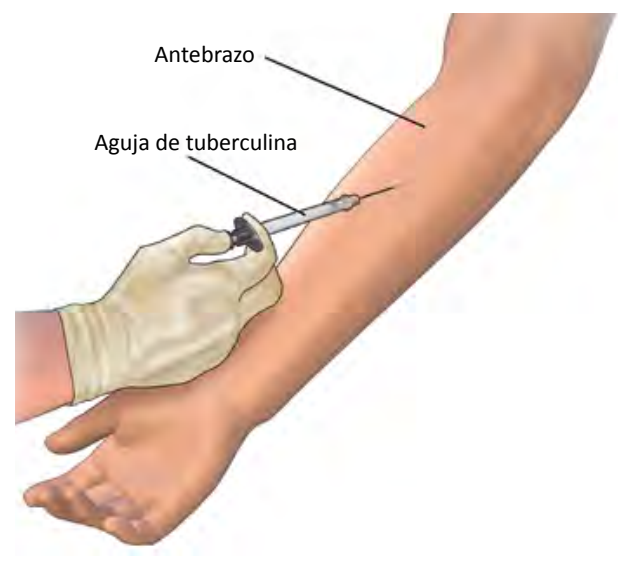

Figura 1. Ilustración de la prueba cutánea de tuberculina. Tomado de Skin Test en Wikimedia Commons, por BruceBlaus, 2017, obtenido de https://commons.wikimedia.org/wiki/ File:TB_Skin_Test.png. Creative Commons Attribution-Share Alike 4.0 International license.

La producción de la tuberculina se estandarizó bajo la denominación de derivado proteico purificado (PPD), que se empezó a utilizar en 1934 [3]. En 1939, Seibert y Glenn produjeron un lote de PPD conocido como PPD estándar, o PPD-S, que hoy en día se utiliza como el estándar de referencia internacional [1]. Actualmente, la prueba de tuberculina en piel es el método estándar para el diagnóstico de tuberculosis latente; en esta prueba, el PPD se inocula por vía intradérmica en el antebrazo y 48 a 72 horas después se determina la reacción mediante la medición del diámetro de la induración que se produce en la piel. El criterio para establecer una prueba como positiva depende de la prevalencia regional de la enfermedad y de la dosis de PPD utilizada [4]. 
La prueba de tuberculina en piel se fundamenta en que la infección por Mycobacterium tuberculosis induce una respuesta inmune contra antígenos micobacterianos mediada por células, especialmente linfocitos T CD4 ${ }^{+}$[5]. La exposición subsecuente del individuo, por vía intradérmica, a los antígenos de la micobacteria que puedan ser reconocidos por los linfocitos $T$ específicos, induce una reacción de hipersensibilidad retardada tipo IV que refleja la sensibilidad del individuo a los antígenos en las horas sucesivas al reto [6]. Después de la inyección del PPD, el sitio de la punción es infiltrado en forma rápida ( $4 \mathrm{~h}$ ) por neutrófilos y, más tarde (12 h), por linfocitos $\mathrm{T}$ y monocitos que se distribuyen alrededor de las vénulas, donde, además, el fibrinógeno liberado desde los vasos sanguíneos al tejido circundante se convierte en fibrina [7]. Los depósitos de fibrina, y en menor grado la acumulación de linfocitos $T$ y monocitos, en el espacio extravascular alrededor de la punción causan la inflamación y la induración de la piel [8].

Algunos estudios sobre la utilidad diagnóstica de la prueba de tuberculina en piel mostraron que su aplicación en poblaciones bien definidas, desde el punto de vista epidemiológico, inducía respuestas diferentes [9]. Las dosis de tuberculina de $1 \mu \mathrm{g}$ producían mayor induración en los individuos que tenían enfermedad activa y en sus contactos, en comparación con aquellos con probabilidad muy baja de presentar la infección tuberculosa latente; sin embargo, con dosis altas de tuberculina $(1 \mathrm{mg}$ ) las induraciones tendieron a igualarse en todos los individuos [10]. Esta observación cuestionó la especificidad de la prueba [11], lo cual se puede deber a que el PPD contiene más de 200 proteínas, muchas de las cuales son compartidas con micobacterias no tuberculosas y Mycobacterium bovis BCG [12]. Por lo tanto, la res- puesta al PPD puede ser el resultado de la infección por Mycobacterium tuberculosis o micobacterias no tuberculosas [13] o de la vacunación con BCG [14].

En un estudio realizado en diferentes escuelas de Kenia, donde los niños fueron inoculados con PPD de Mycobacterium tuberculosis en el antebrazo derecho y con PPD de micobacterias no tuberculosas en el antebrazo izquierdo, se demostró la inespecificidad de la prueba. Aproximadamente, la mitad de los niños (47\%) no presentó reacción en ningún antebrazo; el $6,1 \%$ solo reaccionó contra el PPD de Mycobacterium tuberculosis, el 22,7\% solo contra el PPD de micobacterias no tuberculosas y el $24 \%$ contra ambos tipos de PPD [15].

La inespecificidad de la prueba también se puede deber a falsos positivos por reactividad cruzada, lo que dificulta la real identificación de individuos con infección tuberculosa latente. En Inglaterra y Malawi, en un estudio comparativo de la respuesta a la prueba de tuberculina en piel antes y un año después de la vacunación con BCG en adolescentes y adultos jóvenes sin cicatriz de BCG, los autores reportaron un incremento en la reacción a la prueba un año después de la vacunación en ambas poblaciones [14], lo que evidencia la falta de especificidad de esta prueba para la detección de la infección.

Además de la baja especificidad, la prueba de tuberculina en piel presenta una pobre sensibilidad en individuos con alto riesgo de desarrollar tuberculosis activa. La función deficiente de los linfocitos $T$ en los individuos inmunocomprometidos, interpretada a veces como anergia o simplemente como hiporrespuesta de las céluas específicas de antígeno, puede resultar en falsos negativos 
[16]. Las dificultades en la aplicación e interpretación de la prueba de tuberculina en piel llevan, con frecuencia, a resultados falsos [17]; además, la prueba no discrimina entre la infección tuberculosa latente y la tuberculosis activa [3], lo cual limita su utilidad.

\section{Ensayos de acumulación de interferón gamma (IFN-Y)}

El desarrollo de nuevas estrategias diagnósticas para la infección tuberculosa latente ha sido difícil por la falta de un estándar de referencia. Se considera que la proximidad y mayor contacto con un paciente con tuberculosis activa (caso índice) es la condición más favorable para adquirir la infección tuberculosa latente. Por tanto, la sensibilidad de una nueva prueba diagnóstica para este tipo de infección no se debe comparar de manera directa con la prueba de tuberculina en piel. Una prueba superior a la prueba de tuberculina en piel, en cuanto a sensibilidad, debe tener una positividad mayor asociada al grado mayor de contacto con el caso índice. La especificidad se debe obtener cuando el resultado positivo sea independiente de la vacunación o el contacto con micobacterias no tuberculosas [3].

En las dos últimas décadas se han desarrollado nuevas herramientas para el diagnóstico de infección tuberculosa latente como el QuantiFERON-TB, el QuantiFERON-TB Gold y el T-SPOT ${ }^{\circledR}$.TB. El principio de estas pruebas es la detección del IFN- $\gamma$ liberado por los linfocitos $\mathrm{T}$, obtenidos a partir de una muestra de sangre total y estimulados en cultivo con antígenos de Mycobacterium tuberculosis, o la detección de linfocitos $T$ productores de IFN- $\gamma$. El QuantiFERON-TB utiliza como estímulo el PPD, por lo que se considera que carece de especificidad [3].
El QuantiFERON-TB Gold y el T-SPOT ${ }^{\circledR}$.TB estimulan los linfocitos $T$ con antígenos específicos codificados en la región genómica de diferenciación 1 (RD1) de la micobacteria. Esta región de 9,5 kb, que está presente en todas las cepas de Mycobacterium tuberculosis, Mycobacterium bovis [18-20] y en cuatro micobacterias no tuberculosas (Mycobacterium kansasii, Mycobacterium szulgai, Mycobacterium flavescens y Mycobacterium marinum) [21], no se detecta en las cepas de Mycobacterium bovis BCG, según ensayos de hibridación substractiva reportados por Mahairas y colaboradores (1996) [18].

La deleción de RD1 en la cepa Mycobacterium bovis BCG es lo que explicaría, en parte, su carácter de microorganismo atenuado, ya que su presencia se ha correlacionado con la virulencia de las micobacterias del complejo tuberculosis [20]. La región RD1 consta de nueve genes que codifican para las proteínas Rv3871-Rv3879c, dentro de las cuales se encuentran los antígenos ESAT-6 (del inglés, Early Secreted Antigenic Target- 6 o Rv3875) y CFP-10 (del inglés, Culture Filtrate Protein-10 o Rv3876) [18-20]. Estas proteínas son secretadas activamente por la micobacteria al ambiente extracelular [22] y son altamente inmunogénicas [23,24]; características por las cuales estas moléculas se utilizan como antígenos en las pruebas QuantiFERON-TB Gold y T-SPOT ${ }^{\circledR}$.TB.

Arend y colaboradores (2001) [25] compararon la prueba de tuberculina en piel con la secreción de IFN- $\gamma$ en respuesta al ESAT-6 y al PPD en cultivos de sangre total de 44 contactos cercanos de un paciente con tuberculosis activa. Estos autores observaron que, mientras algunos contactos con prueba de tuberculina en piel negati- 
va respondieron al PPD en los cultivos de sangre total, ninguno respondió in vitro a la estimulación con ESAT-6 y CFP-10, lo cual interpretaron como una mayor especificidad (100\%) y menor sensibilidad $(67 \%)$ de la prueba con antígenos propios de $\mathrm{Myco-}$ bacterium tuberculosis en comparación con la prueba con PPD (especificidad del $72 \%$ y sensibilidad del $100 \%$ ).

Johnson y colaboradores (1999) [26] también reportaron una mayor especificidad del QuantiFERON-TB Gold, usando ESAT6 como estímulo, en comparación con el QuantiFERON-TB y la prueba de tuberculina en piel. En otro estudio, 60 estudiantes australianos que no tenían exposición establecida a Mycobacterium tuberculosis o a micobacterias no tuberculosas, y que no habían recibido el BCG, fueron vacunados con esta para evaluar la respuesta antes y después de la inmunización mediante prueba de tuberculina en piel y cultivos de sangre total estimulados con ESAT- 6 o PPD. Antes de la vacunación todos los estudiantes tuvieron resultados negativos en las pruebas, pero cinco meses después de la inmunización con BCG el 13\% presentó una reacción mayor o igual a $10 \mathrm{~mm}$ en la prueba de tuberculina en piel y $20 \%$ fueron positivos en la detección de IFN- $\gamma$ en los cultivos de sangre total estimulados con PPD; por el contrario, antes y después de la inmunización los estudiantes presentaron resultados negativos en la prueba de QuantiFERON-TB Gold con ESAT-6 [26]. Brock y colaboradores (2001) [27] también mostraron una mayor especificidad de las pruebas con ESAT-6 y CFP-10 comparadas con las de PPD en individuos vacunados con BCG frente a los no vacunados.

A pesar de los buenos resultados de estos ensayos en la detección de individuos con infección tuberculosa latente, su utilidad en el diagnóstico de pacientes con enfermedad activa es escasa $[17,28,29]$. Pathan y colaboradores (2001) [30] reportaron una baja frecuencia de linfocitos $\mathrm{T} \mathrm{CD}^{+}$ secretores de IFN- $\gamma$ específicos de ESAT-6 en individuos con tuberculosis activa, en comparación con aquellos con infección tuberculosa latente. En la actualidad, los ensayos de acumulación de IFN- $\gamma$ se consideran como el mejor método para determinar cuáles personas están infectadas con Mycobacterium tuberculosis, aunque su utilidad es limitada en el diagnóstico de la tuberculosis activa.

\section{Diagnóstico de tuberculosis activa}

La forma más frecuente de la tuberculosis es la pulmonar. El diagnóstico microbiológico convencional se basa en la detección del bacilo en al menos una de tres muestras de esputo recolectadas en tres días diferentes. Estas muestras se someten a tinción de ácido alcohol resistencia para evaluar al microscopio la presencia del microorganismo y se llevan a cultivo en medio LowensteinJensen, lo cual es necesario para confirmar el diagnóstico [29].

Un porcentaje alto de los casos de tuberculosis activa se diagnostica de acuerdo con los hallazgos clínicos, compatibles con el riesgo epidemiológico, y la infección se confirma por la respuesta al tratamiento anti-tuberculoso [3]. Se considera que el diagnóstico microbiológico es el ideal y, en la actualidad, la tinción ácido alcohol resistente del bacilo, los cultivos micobacterianos y, más recientemente, la amplificación de los ácidos nucleicos son las metodologías más utilizadas. 


\section{Detección directa de la bacteria}

\section{Tinción ácido alcohol resistente}

En 1882 Robert Koch describió la tinción ácido alcohol resistente para detectar el bacilo que causa la tuberculosis [31]; más de 130 años después, este método para la detección de micobacterias en esputo (baciloscopia) continúa siendo la más usada por su facilidad y rapidez y por su bajo costo. La tinción se basa en el alto contenido de lípidos de la pared celular de la micobacteria que le confiere resistencia a la decoloración con alcohol ácido. Inicialmente, el bacilo se tiñe con fuscina, se decolora con alcohol ácido $y$, posteriormente, se tiñe con una solución de contraste como el azul de metileno. Las dos tinciones ácido alcohol resistentes más utilizadas son la de Ziehl-Neelsen (véase figura 2) y la de Kinyoun [29].

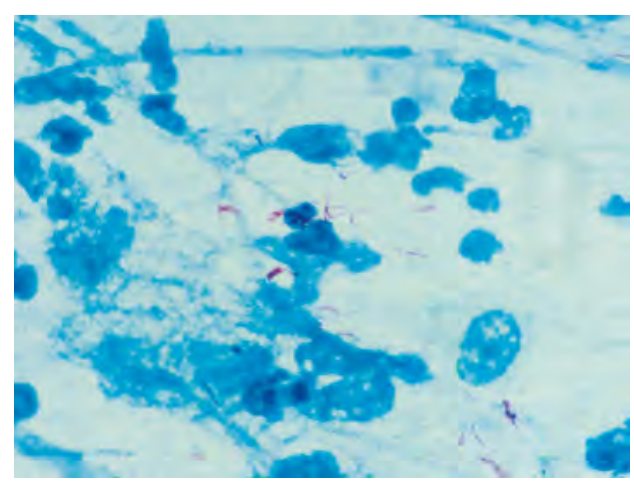

Figura 2. Baciloscopia de esputo teñida con Ziehl-Neelsen positiva para bacilos ácido alcohol resistentes (BAAR). Cortesía de la Escuela de Microbiología, Universidad de Antioquia. Medellín, Colombia.

Desafortunadamente, la sensibilidad de la tinción es limitada. Para que un esputo resulte positivo mediante microscopía debe contener entre 5.000 a 10.000 bacilos/mL [32]. El $50 \%$ al $60 \%$ de los pacientes con tuberculo- sis pulmonar activa son negativos (pacientes paucibacilares), aunque la sensibilidad tiende a ser mayor en pacientes con enfermedad cavitaria y menor en pacientes con tos débil o con una enfermedad menos avanzada [3]; además, la negatividad en la tinción de esputo no elimina el diagnóstico de tuberculosis, particularmente cuando la sospecha clínica y el riesgo epidemiológico son altos.

Otra limitación de esta técnica es que alrededor del $30 \%$ de los pacientes con tuberculosis no expectoran y la producción de esputo debe ser inducida [33]; además, la tinción ácido alcohol resistente no indica la viabilidad del microorganismo ni lo identifica como Mycobacterium tuberculosis y es únicamente informativa en individuos con tuberculosis pulmonar activa [17].

\section{Cultivo}

La confirmación del diagnóstico de la infección pulmonar activa se debe realizar mediante el cultivo en medios como el Löwenstein-Jensen (véase figura 3), aún cuando la microscopía es positiva, debido a que los bacilos del grupo micobacterias no tuberculosas también son ácido alcohol resistentes. Se estima que las técnicas tradicionales de cultivo de esputo requieren 10 a 100 micobacterias viables $/ \mathrm{mL}$ de muestra, que tienen una alta especificidad (alrededor del $98 \%$ ) [34] y que la sensibilidad es superior (80\% al $93 \%$ ) a la microscopía de esputo [35]. Además, el cultivo permite realizar la prueba de susceptibilidad a fármacos, así como la genotipificación y la especiación para instaurar el tratamiento antibiótico adecuado y para propósitos epidemiológicos, respectivamente [36]. La mayor limitación de los cultivos es el lento crecimiento de Mycobacterium tuberculosis para su aislamiento e identificación; el procedimiento requiere de seis a ocho semanas, lo que re- 


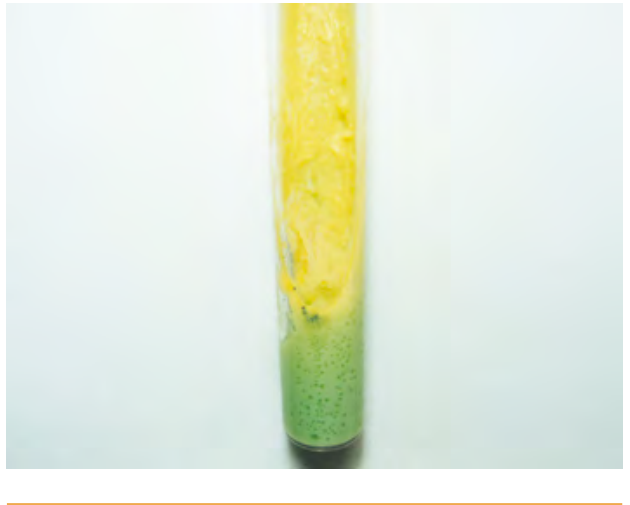

Figura 3. Cultivo de esputo en medio de Löwenstein-Jensen. Obsérvense colonias de color blanco-crema, secas, rugosas y opacas compatibles con Mycobacterium tuberculosis. Cortesía de la Escuela de Microbiología, Universidad de Antioquia. Medellín, Colombia.

trasa el inicio del tratamiento y aumenta la probabilidad de que el paciente empeore su estado clínico e infecte a más contactos [3].

Para acelerar la obtención de los resultados se han desarrollado metodologías alternativas para el cultivo de Mycobacterium tuberculosis. El ensayo radiométrico BACTEC 460 TB (BD, Maryland, Estados Unidos), específico para la detección de Mycobacterium tuberculosis, es un buen ejemplo de ello. Esta técnica utiliza medio de cultivo $7 \mathrm{H} 12$ con ácido palmítico marcado con ${ }^{14} \mathrm{C}$ para detectar la presencia de la micobacteria con base en su metabolismo más que en su crecimiento. Cuando el ${ }^{14} \mathrm{C}$ es metabolizado, el ${ }^{14} \mathrm{CO}_{2}$ producido es detectado por el sistema BACTEC 460 TB y reportado en términos de índice de crecimiento bacteriano. Después de la obtención del índice de crecimiento se puede adicionar al cultivo $p$ nitro-alfa-acetil-beta-hidroxi-propiofenona (NAP), compuesto intermedio en la síntesis del cloranfenicol, que inhibe el crecimiento de las micobacterias pertenecientes al complejo tuberculosis (Mycobacterium tubercu-
Iosis, Mycobacterium bovis, Mycobacterium africanum y Mycobacterium microti) pero no el de las micobacterias no tuberculosas [37]. De esta forma, se añade especificidad al método.

\section{Amplificación de ácidos nucleicos}

Se denominan pruebas de complemento porque en la actualidad no reemplazan a las técnicas convencionales de diagnóstico. Existen múltiples blancos para amplificar que incluyen fragmentos de ADN y ARN. Para la tuberculosis el fragmento que se estudia $y$ amplifica con más frecuencia es la secuencia de inserción 6110 (IS6110), altamente conservada y específica de Mycobacterium tuberculosis y sin homólogos en otras especies de Mycobacterium (véase figura 4) [38]. A diferencia de la microscopía de esputo, que es de baja sensibilidad, y de los cultivos, que necesitan largos tiempos de incubación, las pruebas de amplificación de ácidos nucleicos son rápidas, sensibles (mayor o igual al $80 \%$ ) y altamente específicas (98\% al 99\%) [3943]. Se estima que tan solo 10 bacilos en una muestra son necesarios para obtener una prueba positiva; sin embargo, en individuos con un examen microscópico de esputo negativo (pacientes paucibacilares) la sensibilidad es menor [34].

\section{Diagnóstico en individuos paucibacilares}

Los individuos paucibacilares son pacientes con tuberculosis incapaces de producir esputo o cuyo examen directo de esputo es negativo. Como se mencionó anteriormente, el $50 \%$ al $60 \%$ de los pacientes con tuberculosis pulmonar activa son paucibacilares [17]. Con frecuencia, los pacientes adultos coinfectados con el $\mathrm{VIH}$, así como 


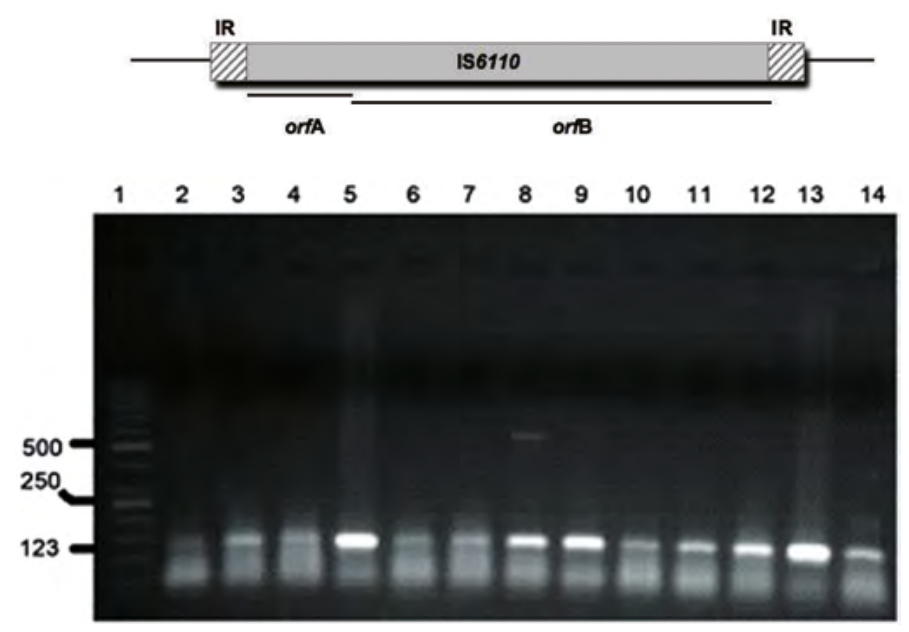

Figura 4. Producto de amplificación por PCR de la secuencia IS6110 de Mycobacterium tuberculosis en gel de agarosa. Carriles: 1: marcador de peso molecular (50 pb), 2: muestra de esputo negativa, 3-14: muestras de esputo positivas. Obsérvese fragmento de 123 pb, correspondiente a IS6110. Tomado de "Diagnostic Accuracy of IS6110 Insertion Gene, Hsp65, and Xpert MTB/RIF for Rapid Diagnosis of Pulmonary Tuberculosis" por Abdelhaleem y colaboradores, 2017, Journal of Tuberculosis Research, 5, p. 4. Copyright (C) 2017 por los autores y Scientific Research Publishing Inc. Creative Commons Attribution International License (CC BY 4.0) [44].

los niños, son paucibacilares y se les deben realizar diferentes pruebas, porque en ellos la enfermedad progresa con gran rapidez y se manifiesta en formas severas que causan la muerte. En general, un porcentaje alto de individuos paucibacilares no se diagnostican a tiempo $[45,46]$ y presentan consecuencias fatales [47].

\section{Adultos paucibacilares}

En los años 2003 y 2006, la OMS realizó las siguientes recomendaciones para el diagnóstico de tuberculosis pulmonar en individuos paucibacilares $[1,16,48]$ : a) realizar al menos tres exámenes directos de esputo; b) si los exámenes siguen siendo negativos el paciente se debe medicar con antibióticos de amplio espectro, excepto fármacos antituberculosos y fluoroquinolonas; c) si el paciente no mejora con el tratamiento farmacológico se debe realizar otra microsco- pía de esputo; d) si el resultado es de nuevo negativo, se debe hacer radiografía de tórax que indicaría alteraciones compatibles con tuberculosis [1]. Si la infraestructura del centro de salud lo permite, cada uno de los esputos se debe cultivar para observar el crecimiento de Mycobacterium tuberculosis [49]; además, se deben realizar otras técnicas de mayor complejidad como lavados gástricos y broncoalveolares; estas técnicas se explicarán más adelante.

\section{Tuberculosis infantil}

La población infantil es una de las más vulnerables a la tuberculosis. Sin tratamiento oportuno la mayoría de niños menores de un año de edad mueren por la severidad de la enfermedad $[47,50]$. El diagnóstico de tuberculosis en niños es complicado debido: a) lo similar de la tuberculosis a enfermedades comunes de la infancia, como neumo- 
nía, infecciones virales, bacterianas y malnutrición [51], b) la ausencia de una prueba de referencia con eficiencia comprobada [52], c) la inhabilidad de los pacientes infantes para expectorar $[45,46]$, d) la característica de ser paucibacilares $[45,46,53]$ y e) la baja sensibilidad del cultivo, aún cuando se induzca el esputo o se utilicen aspirados gástricos que, a pesar de ser la prueba estándar para el diagnóstico de tuberculosis en adultos, la sensibilidad de esta prueba en niños tan solo alcanza el $30 \%$ al $40 \%[45,54]$. Además, los síntomas en los niños no son específicos; hasta el $50 \%$ de los infantes pueden ser asintomáticos en los estadios tempranos de la enfermedad [47] y suelen ser más atípicos cuando existe coinfección por el VIH [55].

El diagnóstico de tuberculosis en los niños se fundamenta en: a) datos epidemiológicos: exposición a un caso índice; b) datos clínicos: síntomas respiratorios crónicos, como tos, fiebre, fatiga y sibilancias, que permanecen después del tratamiento con antibióticos de amplio espectro; pérdida de peso y retraso en el desarrollo $[47,56]$ y c) datos radiológicos compatibles con tuberculosis $[47,56,57]$. A esto se suma una prueba de tuberculina en piel positiva $[47,56]$.

\section{Aproximación diagnóstica a la tuberculosis en niños según las recomendaciones de la OMS}

Dentro de los criterios diagnósticos que se aplican existen divergencias. Por ejemplo, no es tan claro qué indicaciones se requieren para aplicar una u otra estrategia de aislamiento microbiológico (cuerda dulce frente a esputo inducido), el usar o no tomografía de tórax o estudio endoscópico. En los últimos años, además, se han producido modificaciones en la interpretación de las designadas pruebas clásicas. Como ya se mencionó, la prueba de tuberculina en piel ha empezado a ser reconsiderada debido a la emergencia de las pruebas de producción de IFN- $\gamma$ frente antígenos específicos de Mycobacterium tuberculosis, previamente mencionadas, y las técnicas de biología molecular. No obstante, todos estos métodos disponibles continúan siendo insuficientes para asegurar un abordaje diagnóstico óptimo de esta enfermedad, sobre todo en los niños pequeños y en los inmunodeprimidos, con los que hay aún menor experiencia.

Dadas las dificultades que se establecen en las aproximaciones a la definición diagnóstica de la tuberculosis, la OMS hace recomendaciones sobre el proceso sistemático para la identificación de los contactos de pacientes infectados que tienen la enfermedad [58], o están en mayor riesgo de desarrollarla. La definición y la identificación de los contactos incluyen una entrevista al caso índice para acceder a la información de sus contactos y una evaluación del riesgo de desarrollo de la tuberculosis, generalmente con base en la presencia de síntomas compatibles con la enfermedad. Así, la OMS recomienda que el diagnóstico de la tuberculosis en los niños se debe basar en la evaluación exhaustiva de todas las pruebas derivadas de una historia detallada de la exposición, el examen clínico y las investigaciones pertinentes. El enfoque propuesto por la OMS para el diagnóstico de la tuberculosis en los niños se basa en la evidencia ya publicada [52,59-65] y se apoya fuertemente en la opinión de expertos.

Es importante tener en cuenta que la mayoría de los niños con tuberculosis tienen formas pulmonares. Aunque su confirmación bacteriológica no siempre es factible, la OMS recomienda identificar la micobac- 
teria por microscopía y cultivo, siempre que sea posible. Entre las recomendaciones más recientes y más apoyadas está la aplicación de pruebas genotípicas, como la Xpert MTB/ $\mathrm{Rif}^{\circledR}$, que permiten detectar la presencia de Mycobacterium tuberculosis y, simultáneamente, la resistencia a la rifampicina a partir de diversos tipos de muestras (esputo, lavado y aspirado gástricos) según lo indicado para la forma clínica. Estas recomendaciones no se aplican a las muestras de heces, orina o sangre, debido a la falta de datos sobre la utilidad de la Xpert MTB/Rif ${ }^{\circledR}$ en estos especímenes [58].

La Xpert MTB/Rif ${ }^{\circledast}$ permite concentrar los bacilos a partir de muestras de esputo y aislar su material genómico mediante sonicación para, posteriormente, amplificar el ADN genómico por reacción en cadena de la polimerasa (PCR) semicuantitativa [66-68]. El proceso identifica las mutaciones de resistencia a la rifampicina, clínicamente relevantes, ubicadas en el gen de la ARN polimerasa beta (rpoB), usando sondas fluorescentes. La obtención de resultados a partir de muestras de esputo sin procesar se logra en solo 90 minutos, con riesgos biológicos mínimos, y requiere de poco entrenamiento técnico por parte del personal que realiza la prueba [67]. Incluso, esta prueba fue implementada como una estrategia tan simple que se podría llevara cabo en el consultorio de un médico, si es necesario.

A pesar de las recomendaciones de la OMS, en una revisión para evaluar la precisión diagnóstica de la Xpert MTB/Rif ${ }^{\oplus}$ se encontró que, cuando se utiliza como una prueba inicial para reemplazar la baciloscopia, alcanza una sensibilidad del $88 \%$ y una especificidad del $98 \%$ [69-71]; sin embargo, cuando se utiliza como un primera aproximación para casos con baciloscopia negativa la sensibilidad es solo del $67 \%$ y la especificidad del $98 \%$ [69].
En un estudio clínico para evaluar la sensibilidad de la prueba Xpert MTB/Rif ${ }^{\oplus}$ en pacientes con cultivo positivo para tuberculosis se encontró que la prueba identificó a 551 de 561 (98,2\%) pacientes con tuberculosis con frotis positivo y 124 de 171 (72,5\%) pacientes con tuberculosis con frotis negativo. La prueba fue específica en 604 de $609(99,2 \%)$ pacientes sin tuberculosis. Entre los pacientes positivos para tuberculosis por baciloscopia y cultivo, una segunda prueba de Xpert MTB/ Rif $^{\oplus}$ aumentó la sensibilidad en un $12,6 \%$ y una tercera en $5,1 \%$, hasta un valor total de sensibilidad de $90,2 \%$. En comparación con las pruebas fenotípicas de susceptibilidad a fármacos, las pruebas de Xpert MTB/Rif ${ }^{\circledR}$ identificaron correctamente 200 de 205 $(97,6 \%)$ pacientes con bacterias resistentes a la rifampicina y 504 de 514 (98,1\%) pacientes con bacterias sensibles a la rifampina. La secuenciación resolvió todos menos dos casos a favor del ensayo Xpert MTB/ $\mathrm{Rif}^{\circledR}$, pudiéndose colegir que esta prueba proporcionó la detección sensible de la tuberculosis y de la resistencia a la rifampicina directamente del esputo no tratado en menos de 2 horas, con un mínimo de tiempo de intervención [72].

\section{Esputo inducido}

El procedimiento para provocar la producción de esputo se basa en la administración de solución salina hipertónica (3\% al 15\%) estéril, mediante un nebulizador ultrasónico, durante la cual se induce al paciente a que expectore (véase figura 5). Antes de la nebulización los pacientes reciben salbutamol inhalado para prevenir el broncoespasmo [73]. Inicialmente, la técnica fue utilizada en la citología de esputo para el diagnóstico de cáncer de pulmón [3]; luego, en 1961 fue descrito su uso por primera vez 


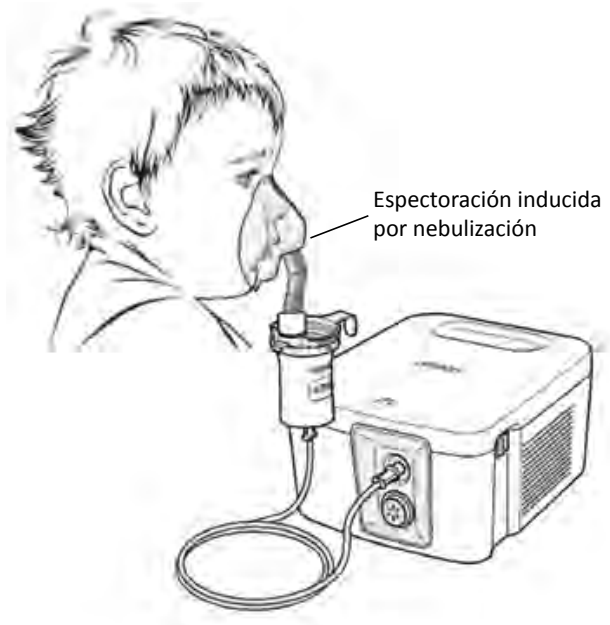

Figura 5. Espectoración inducida por nebulización.

para el diagnóstico de la tuberculosis activa [33]. Desde entonces, varios estudios han analizado la efectividad del método.

En China, a finales de la década de los noventa, se estudiaron 1.648 individuos entre 13 y 80 años de edad con sospecha de tuberculosis, pero con producción de esputo escasa, o ausente, o con esputos negativos al examen directo. Después de la inducción del esputo, el diagnóstico de la tuberculosis se confirmó en 558 individuos mediante tinción ácido alcohol resistente o cultivo (antes de la inducción 353 habían sido negativos en la microscopía directa, 97 habían producido un esputo inadecuado y 108 no habían producido esputo); además, los estudios fueron un $90 \%$ más económicos que la broncoscopia [74].

En otro estudio, en Malawi, la inducción de esputo se realizó en 82 adultos sospechosos de tuberculosis pulmonar con esputos negativos al examen directo o que habían sido incapaces de producir esputo. En 73 de 82 individuos la inducción de esputo fue exitosa; 18 de esos 73 resultaron positivos al examen directo por microscopía y cultivo (antes de la inducción, cinco habían sido negativos al examen directo y 13 no habían producido esputo). Además, 12 individuos con esputo inducido que resultaron negativos al examen directo tuvieron cultivos positivos [75]. Por otra parte, en Sudáfrica se realizó una investigación similar, en la cual la inducción de esputo fue exitosa en 36 de 51 individuos sospechosos de tuberculosis; 15 de estos 36 pacientes resultaron positivos en la tinción ácido alcohol resistente y los 16 restantes fueron diagnósticados con neumonía o carcinoma de pulmón [76].

Estos estudios demuestran que la inducción de esputo incrementa la sensibilidad del diagnóstico de la tuberculosis pulmonar; sin embargo, la Sociedad Torácica Americana (AST, del inglés, American Thoracic Society) considera que la tos inducida por este método puede ser violenta y descontrolada, y recomienda que para evitar la transmisión de la infección los pacientes se ubiquen en una cabina o campana equipada con un filtro de aire de partículas de alta eficiencia [77]; además, que el procedimiento debe ser realizado por personal calificado que use la protección apropiada $[1,48]$.

\section{Lavado gástrico}

El lavado gástrico se recomienda en pacientes, particularmente niños, que no producen esputo aún después de la inducción mediante nebulización. Alrededor de $50 \mathrm{~mL}$ de contenido gástrico se pueden recuperar en la mañana, después de un ayuno de 8 a 10 horas, con una sonda nasogástrica, hueca, multiperforada en su extremo distal, que se introduce hasta el estómago para administrar pequeños volúmenes de líquido que luego se aspiran (véase figura 6) [16]. 


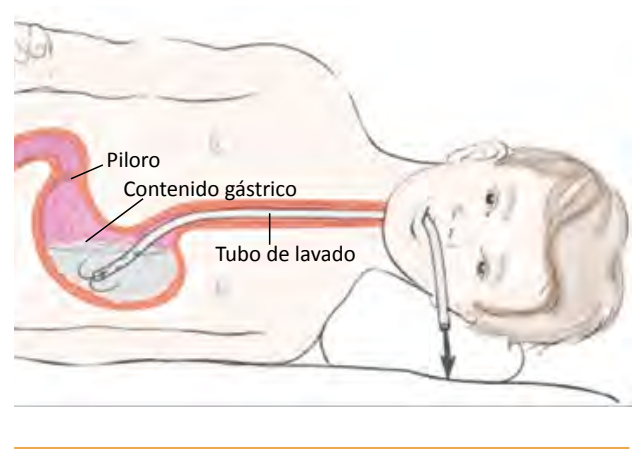

Figura 6. Toma de muestra de lavado gástrico en niños en posición decúbito lateral izquierdo.

En un estudio de 20 niños con sospecha de tuberculosis se realizó lavado gástrico matinal durante tres días consecutivos y un lavado broncoalveolar el último día del muestreo; tanto los lavados broncoalveolares como los lavados gástricos fueron negativos en la tinción ácido alcohol resistente, 2 de 20 cultivos de lavados broncoalveolares fueron positivos para Mycobacterium tuberculosis, así como los cultivos de los lavados gástricos de los mismos individuos; además, ocho cultivos de lavados gástricos diferentes resultaron positivos, para una positividad total del $50 \%$. Estos resultados indican que para el diagnóstico bacteriológico de tuberculosis pulmonar en niños la obtención de lavados gástricos durante tres días consecutivos es más eficiente que el lavado broncoalveolar [77].

Uno de los inconvenientes del lavado gástrico es que debe ser neutralizado inmediatamente después de su recolección, a causa del $\mathrm{pH}$ ácido que puede alterar la viabilidad de la micobacteria; por tal razón, se recomienda solo en pacientes hospitalizados [78]. Una desventaja adicional es la invasividad del procedimiento.

\section{Lavado broncoalveolar}

El lavado broncoalveolar es una estrategia que permite estudiar el fluido epitelial del tracto respiratorio y mediante la cual es posible analizar componentes celulares y no celulares que pueden brindar información sobre el estado de las vías aéreas. Algunos broncoscopistas prefieren la sedación para evaluar la función de las vías aéreas y tener un mejor retorno del lavado broncoalveolar, aunque los estudios recientes favorecen el uso de la anestesia general. En la actualidad, se utilizan broncoscopios flexibles, de forma tubular, que en el extremo tienen una cámara microscópica y haces de fibra óptica para conducir la luz, y un procesador de imágenes para la cámara (véase figura 7) [79].

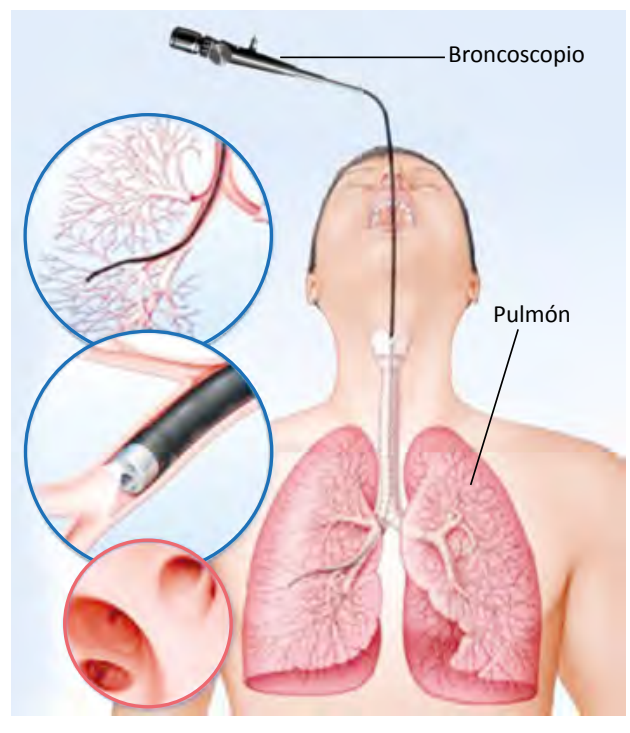

Figura 7. Toma de muestra de lavado broncoalveolar.

Para la obtención del lavado broncoalveolar el broncoscopio se ubica en alguno de los lóbulos pulmonares del paciente, por lo general, el lóbulo que en la radiografía de tórax presenta las irregularidades [79], y se instila solución salina. El porcentaje de fluido recu- 
perado es del $50 \%$ al $80 \%$ y depende de la estabilidad del broncoscopio, de la succión y de la presión negativa aplicada $[79,80]$. En un estudio de 20 individuos con sospecha de tuberculosis pulmonar el diagnóstico se confirmó en 17 de ellos, mediante el cultivo de los lavados broncoalveolares en medio Lowenstein-Jensen [81]. De modo similar, en otra investigación, el 83,3\% de individuos sospechosos de tuberculosis se diagnosticaron con la enfermedad mediante cultivo de lavado broncoalveolar [82].

Aunque el lavado broncoalveolar incrementa la sensibilidad del diagnóstico en individuos paucibacilares, tiene algunos inconvenientes: a) los agentes tópicos utilizados para anestesiar la mucosa de las vías aéreas pueden ser deletéreos para Mycobacterium tuberculosis, por lo cual se deben usar con mucha precaución [83], b) la prueba es invasiva e incómoda para el paciente, c) se requiere de una infraestructura adecuada y de personal especializado y d) el procedimiento puede inducir la producción de esputo durante varios días [84].

\section{La cuerda dulce}

La dificultad en la obtención de muestras pediátricas para el diagnóstico de tuberculosis motivó la invención de otro tipo de procedimiento como "la cuerda dulce». Esta consiste en una cuerda de nailon enrollada dentro de una cápsula de gel. La cuerda se desenrolla a través de un orificio en el extremo de la cápsula a medida que esta desciende hacia el estómago, de modo que la cuerda se cubre con las secreciones gastrointestinales que contienen los microrganismos; tiempo después la cápsula se elimina en las heces. Esta metodología es bien tolerada por los niños y es menos invasiva que el lavado broncoalveolar [85].
De acuerdo con los datos revisados, las técnicas del laboratorio clínico utilizadas de rutina para el diagnóstico de las distintas formas de tuberculosis carecen de sensibilidad y especificidad o requieren de una infraestructura compleja, que no es viable en muchos países en desarrollo. Por esto, es necesario el diseño de estrategias nuevas para identificar la micobacteria, o sus vestigios, en forma rápida y no invasiva. Dichas estrategias deben funcionar como herramientas para el diagnóstico, de modo que se pueda diferenciar de manera oportuna entre las personas no infectadas de aquellas con tuberculosis latente o con tuberculosis activa, ya sean bacilíferos o paucibacilares.

\section{Principios para la utilización de nuevas herramientas diagnósticas}

Se ha demostrado que Mycobacterium tuberculosis secreta de manera activa algunas moléculas, aún cuando es fagocitado por los macrófagos in vitro [86-88] o aspirado por ratones in vivo [89]. Esas moléculas pueden ser proteínas [20,90-93], productos volátiles orgánicos [94-97] y lípidos [86-88,98,99], de los cuales los últimos son los más estables frente a los cambios de temperatura, $\mathrm{pH}$ y degradación y, por lo tanto, son analitos atractivos para evidenciar la presencia de la micobacteria [100].

La gran mayoría de los lípidos secretados por la micobacteria hacen parte de la pared celular, una estructura bastante compleja y exclusiva de las bacterias del género Mycobacterium [100], la cual está ubicada entre la membrana citoplasmática y la cápsula (estructura formada principalmente de polisacáridos tipo glucanos y arabinomananos) (véase figura 8) [101]. Algunos de estos lípi- 


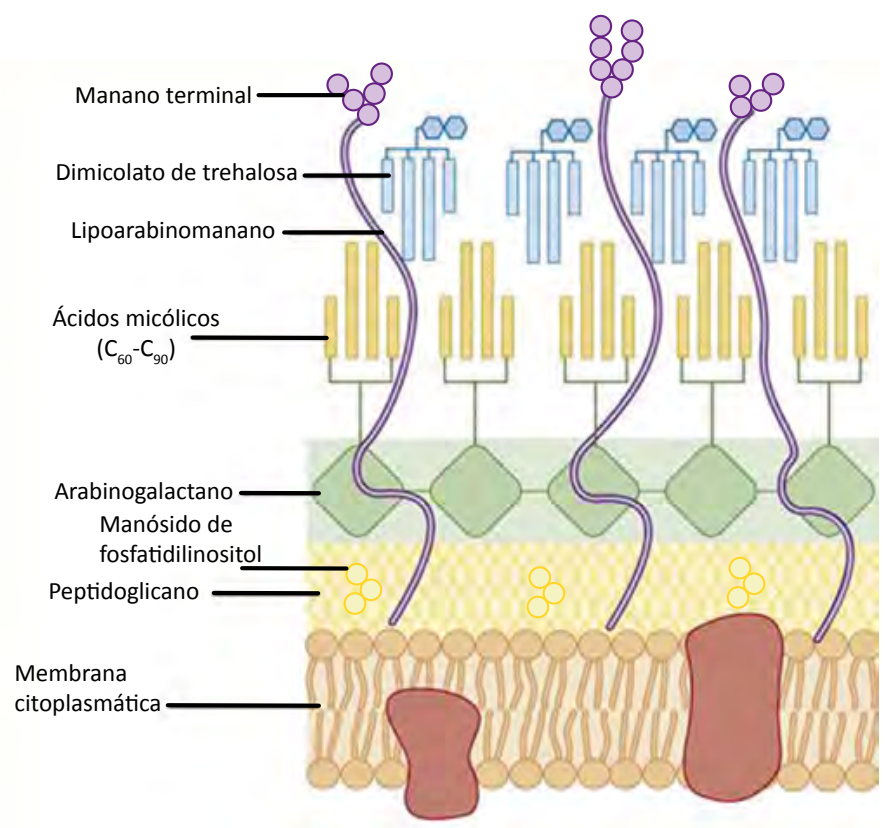

Figura 8. Representación esquemática de la pared celular de micobacterias.

dos liberados de la pared de la micobacteria se pueden detectar, incluso, en el exterior de las células infectadas $[86,87]$.

Por su parte, en los macrófagos derivados de la médula ósea de ratones BALBc infectados con Mycobacterium bovis BCG se han detectado glicolípidos de la micobacteria en organelas diferentes a los fagolisosomas, próximas al aparato de Golgi; hallazgo que se correlaciona con la secreción activa de los metabolitos [86,87]. Algunos estudios posteriores han identificado entre estos glicolípidos a varios derivados del manósido de fosfatidilinositol, el lipoarabinomanano [88] y el dimicolato de trehalosa [87,88], que se consideran exclusivos del género Mycobacterium.

La secreción activa de lípidos micobacterianos también se demostró in vivo en ratones C57BL/6 infectados mediante aerosoles que contenían Mycobacterium bovis BCG, a los que dos semanas después se les tomaron muestras de lavado broncoalveolar, en las cuales se evidenció la presencia de lipoarabinomanano con anticuerpos específicos antilipoarabinomanano [89]. De esta manera, se considera que la detección de estos lípidos podría indicar la existencia de $\mathrm{Myco-}$ bacterium tuberculosis y que es de gran ayuda diagnóstica en aquellos casos en los cuales la micobacteria no es detectable por medios convencionales.

Los manósidos de fosfatidilinositol son glicoconjugados, biológicamente importantes, que representan precursores esenciales comunes de glicolípidos más complejos de la pared celular de las micobacterias entre los que se incluyen el lipomanano, el lipoarabinomanano y el lipoarabinomanano con manano. Los manósidos de fosfatidilinositol y el lipoarabinomanano unidos 
al receptor DC-SIGN (del inglés, dendritic cell-specific ICAM-grabbing non-integrin) pueden inducir niveles comparables de citoquinas como la IL-12 y la IL-10, por lo que ambos se considran que pueden ser ligandos cognatos de este receptor [102]. Es importante destacar que, mientras se ha observado que el lipoarabinomanano con manano aumenta la maduración de las células dendríticas inducida por el lipopolisacárido (LPS) bacteriano y la producción de citoquinas proinflamatorias (TNF- $\alpha$, IL-12 e IL-6), los manósidos de fosfatidilinositol, tanto de Mycobacterium tuberculosis H37Rv como de Mycobacterium bovis, reducen fuertemente el efecto estimulante del lipoarabinomanano con manano [103].

Diferentes fracciones de lípidos de $\mathrm{Myco-}$ bacterium tuberculosis han mostrado, en su mayoría, efectos estimulantes menores o inhibidores sobre la fusión endosomal, mientras que los manósidos de fosfatidilinositol aumentan la fusión endosomal temprana y favorecen la molivilización de calcio. No obstante, el efecto encontrado con los manósidos de fosfatidilinositol puede cambiar dependiendo si el glucolípido se encuentra revisitiendo esferas o inmovilizado en una matriz, lo que sugiere que cuando están vinculados con la bacteria pueden funcionar de una forma diferente a cuando son liberados o desprendidos de ella. Estos hallazgos son consistentes con el hecho de que los manósidos de fosfatidilinositol tienen una actividad biológica altamente especializada in vivo, muy relacionada con la promoción de interacciones con endosomas tempranos que pueden entregar nutrientes a los fagosomas que contienen micobacterias y mantener un $\mathrm{pH}$ relativamente no ácido en su interior [104], pero que previniene la actividad de las enzimas líticas.

El lipoarabinomanano con manano ha sido considerado intrínsecamente como un factor de virulencia, el cual permite diferenciar las bacterias de crecimiento rápido (cuyo lipoarabinomanano carece de residuos de manosa terminales y en su lugar contienen fosfatidilinositol y arabinosa, conocidas como AraLAM) con las de crecimiento lento (aquellas con lipoarabinomanano con manano, conocidas como ManLAM) [105,106]. Es de notar que, desde hace varios años, se reportó que el lipoarabinomanano derivado de una cepa atenuada (H37Ra) de Mycobacterium tuberculosis (AraLAM) era capaz de activar macrófagos e inducir la producción de TNF- $\alpha$, mientras que el lipoarabinomanano derivado de la cepa virulenta de Erdman (ManLAM) era considerablemente reducido en esta actividad.

Un componente crítico en la regulación de muchos genes centrales para la función inmune es el factor de transcripción NF-KB. Se ha demostrado que la inducción de la expresión de TNF- $\alpha$, mediada por lipopolisacáridos, en macrófagos múridos, está regulada, en parte, por el NF-KB [107]. El lipoarabinomanano con manano también ha sido reportado por su capacidad inihibitoria sobre la función de las células T mediante la interferencia directa de la fosforilización de Zap-70, Lck y LAT [108]. Además, inhibe la movilización de calcio y la muerte celular inducida por la infección mediante el incremento de la IL-10 [109].

El dimicolato de trehalosa o factor cordón es una molécula fundamental de la pared celular micobacteriana y uno de los principales componentes tóxicos, responsa- 
ble, en parte, de la baja permeabilidad de la pared y de la formación de agregados bacterianos que le confieren al bacilo, a su vez, una resistencia importante a los fármacos [110].

Teniendo en cuenta que estos lípidos mencionados se secretan de manera activa al espacio intersticial, muestras como la orina, el exhalado respiratorio condensado y el esputo serían matrices menos cruentas e invasivas para la detección de Mycobacterium tuberculosis. Los ácidos micólicos, ácidos grasos y compuestos volátiles orgánicos también han sido estudiados para mejorar el diagnóstico de la tuberculosis.

\section{Lípidos estructurales indicadores potenciales de tuberculosis}

\section{Detección de lipoarabinomanano en orina}

Desde los años treinta la orina se ha propuesto como una matriz adecuada para el diagnóstico de tuberculosis [111]. Esta es una muestra simple de recolectar (en niños y adultos), fácil de procesar y almacenar, y que presenta una probabilidad baja de contaminación [112-115]. Se ha propuesto que, tras la destrucción de la micobacteria en el sitio de la lesión pulmonar, el lipoarabinomanano se secreta o libera y llega por vía sanguínea al riñón, donde se filtra; de este modo, su detección es posible en la orina [111]. Además, a diferencia de la evaluación de la respuesta de linfocitos $T$ o linfocitos $B$, la detección de antígenos es menos vulnerable a las variables del sistema inmune del hospedero [116].
Hamasur y colaboradores (2004) [117] desarrollaron un ELISA basado en la detección de lipoarabinomanano en orina con anticuerpos IgG policlonales, que usaron primero en muestras de ratones inyectados con $100 \mu \mathrm{g}$ de pared celular de la cepa H37Rv de Mycobacterium tuberculosis sonicada. Posteriormente, los autores realizaron un estudio en 15 pacientes de Etiopía con tuberculosis (10 con tuberculosis pulmonar, uno con tuberculosis pleural, dos con tuberculosis peritoneal, uno con linfadenitis tuberculosa y uno con coxitis tuberculosa), a los que se les pidió recolectar muestras de orina, que se esterilizaron por calentamiento a $100^{\circ} \mathrm{C}$ durante 10 minutos y se centrifugaron y filtraron para eliminar el exceso de sales, antes de realizar el ensayo para la detección de lipoarabinomanano. Los resultados fueron positivos en 14 de 15 pacientes y en 4 de 26 individuos sanos que se incluyeron como controles negativos (una enfermera que atendía pacientes con tuberculosis y con reacción positiva a la prueba de tuberculina de $15 \mathrm{~mm}$ y tres individuos con enfermedades pulmonares diferentes a tuberculosis). La prueba tuvo una sensibilidad del 93\% y una especificidad del 96\% [118].

Después de la publicación de estos resultados se desarrolló una primera generación comercial de ELISA para la detección de lipoarabinomanano en orina sin procesar que se utilizó en Tanzania, en un estudio de 231 pacientes con tuberculosis. Mediante esta prueba se detectó el lipoarabinomanano en la orina de 128 de los pacientes, distribuidos en los siguientes grupos: 67 de 82 con tinción de Ziehl Neelsen y cultivo positivo, 38 de 50 con tinción de Ziehl Neelsen negativa y cultivo positivo, 13 de 17 con tinción de Ziehl Neelsen y cultivo negativo y sin respuesta al tratamiento, 
y 10 de 82 con síntomas clínicos compatibles con tuberculosis pulmonar que no pudo ser confirmada. En conclusión, el ELISA para lipoarabinomanano en orina tuvo mejor sensibilidad que la prueba de Ziehl Neelsen [119].

Por otra parte, un estudio más reciente realizado en 109 pacientes categorizados en cuatro grupos, a saber: a) VIH positivos con tuberculosis, b) VIH negativos con tuberculosis diseminada, c) pacientes inmunocomprometidos, VIH negativos con tuberculosis y d) con enfermedades distintas a la tuberculosis, demostró una sensibilidad de la prueba de lipoarabinomanano en orina en los pacientes del primer grupo, con un conteo de células T CD4 ${ }^{+}$de más de 100 células $/ \mathrm{mm}^{3}$, menor o igual que 100 células $/ \mathrm{mm}^{3}$ y menor o igual que 50 células $/ \mathrm{mm}^{3}$, de $38,5 \%, 40,6 \%$ y $45,0 \%$, respectivamente. La especificidad y el valor predictivo fueron mayores al $80 \%$. La sensibilidad de la prueba en el segundo grupo fue del $20 \%$ y en el tercero del $12,5 \%$ y, en ambos, la especificidad y el valor predictivo positivo fueron del $100 \%$. Estos resultados muestran una mejor eficiencia en el diagnóstico de la tuberculosis, que permite predecir la tasa de mortalidad de la infección, particularmente en pacientes coinfectados con tuberculosis y VIH [120].

Desafortunadamente, los buenos resultados de estos reportes iniciales no fueron reproducibles en los estudios posteriores. Peter y colaboradores (2010) [121] encontraron que la detección de lipoarabinomanano en orina en pacientes sudafricanos con tuberculosis y coinfección por VIH tenía menor sensibilidad que la tinción ácido alcohol resistente del esputo. Reither y colaboradores (2009) [111] obtuvieron la mitad de sensibilidad en la detección del lipoarabinomanano en orina en comparación con la microscopía y el cultivo de esputo de pacientes en Tanzania; además, la prueba de lipoarabinomanano resultó positiva tanto en infecciones por Mycobacterium tuberculosis como por micobacterias no tuberculosas.

En otro estudio en India, Daley y colaboradores (2009) [122] reportaron que la sensibilidad del ensayo de detección de lipoarabinomanano en orina fue cinco veces menor que la del cultivo de esputo en medio Lowenstein-Jensen o del sistema BACTEC. A su vez, en un estudio en Zimbabue, Mutetwa y colaboradores (2009) [123] observaron que la detección de lipoarabinomanano en orina tenía la mitad de sensibilidad en los individuos con baciloscopia y cultivo de esputo positivos, y un cuarto de sensibilidad en los individuos con baciloscopia negativa y cultivo de esputo positivo, o con ambas pruebas negativas, pero diagnosticados mediante los hallazgos clínicos y la respuesta al tratamiento antituberculoso.

La mayoría de estudios no aprueban la detección de lipoarabinomanano en orina como una prueba diagnóstica de rutina para la tuberculosis; sin embargo, su mejor utilidad clínica parece estar en individuos infectados por VIH y con inmunosupresión avanzada, ya que muchos de ellos son paucibacilares [116,124-128]. En diferentes investigaciones se ha observado una mayor sensibilidad en la detección de lipoarabinomanano en orina de pacientes con tuberculosis coinfectados con VIH, comparados con pacientes con tuberculosis y VIH negativos $[118,128,129]$. La sensibilidad parece aumentar cuando el conteo de linfocitos T CD4+ es menor a 200 células/ $\mu \mathrm{L}[120,129]$. 
Dheda y colaboradores (2010) [130] observaron que la sensibilidad de la baciloscopia era igual a la de la detección de lipoarabinomanano en individuos con tuberculosis coinfectados con VIH que presentaban recuentos de linfocitos $\mathrm{T} C D 4^{+}$menores a 200/ $\mu \mathrm{L}$. En diferentes estudios en pacientes sudafricanos positivos para la infección por VIH, Lawn y colaboradores reportaron que, en comparación con la baciloscopia de esputo, la detección de lipoarabinomanano en orina tenía mayor sensibilidad y que dicho aumento se asociaba con menores recuentos de linfocitos $\mathrm{T} \mathrm{CD} 4^{+} / \mu \mathrm{L}$ $[116,124,131]$. En concordancia con los datos anteriores, en Sudáfrica, Shah y colaboradores (2009) [132] observaron que la detección del lipoarabinomanano en orina en pacientes VIH positivos presentaba una mayor sensibilidad que la baciloscopia del esputo.

Estos datos sugieren que la detección de lipoarabinomanano en orina, junto con las pruebas de rutina, puede aumentar la eficiencia en el diagnóstico de tuberculosis en individuos inmunosuprimidos; sin embargo, se requieren más estudios al respecto.

\section{Detección de}

\section{lipoarabinomanano en muestras clínicas diferentes a orina}

Aunque la mayoría de estudios han evaluado el ELISA de lipoarabinomanano en orina, su aplicación también se ha analizado en otras muestras clínicas. A partir de la detección de anticuerpos IgG anti-lipoarabinomanano en el suero de 66 pacientes con tuberculosis miliar y pleural (sensibilidad $=72 \%$ y especificidad $=91 \%$ ), Sada y colaboradores (1990) [133] hipotetizaron la presencia de lipoarabinomanano en la sangre de estos pacientes. Dos años después, encontraron que la detec- ción de lipoarabinomanano en suero tenía una sensibilidad de $88 \%$ en pacientes con tuberculosis pulmonar activa y baciloscopia positiva, de $67 \%$ en pacientes con baciloscopia negativa y de $57 \%$ en los pacientes con tuberculosis y SIDA [134]; la especificidad de la prueba fue de $100 \%[133,134]$. Una desventaja de este análisis es la necesidad de tratar las muestras de suero con anticipación para obtener los antígenos micobacterianos presentes en complejos inmunes circulantes, lo que hace que sea un procedimiento engorroso para ser utilizado como una prueba diagnóstica de rutina en el laboratorio clínico.

El esputo también se ha utilizado en la detección de lipoarabinomanano. Pereira y colaboradores (2000) [135] trataron las muestras de esputo de individuos sanos y de pacientes con tuberculosis tratados con $\mathrm{N}$-acetil-L-cisteína y proteinasa $\mathrm{K}$, y obtuvieron una mayor sensibilidad en la detección de lipoarabinomanano en comparación con la baciloscopia, a pesar de que en ambas pruebas el límite de detección fue de 104 micobacterias $/ \mathrm{mL}$. Esta diferencia se podría deber a que el ELISA de lipoarabinomanano utiliza un homogenizado del esputo, mientras que para la microscopía directa se selecciona la porción purulenta del mismo. Dheda y colaboradores, además de detectar lipoarabinomanano en orina, realizaron ensayos en esputo tratado con agentes reductores como el ditiotreitol, cuyos resultados fueron desalentadores y mostraron que los anticuerpos policlonales anti-lipoarabinomanano reaccionaron con microorganismos de la microbiota normal como Candida spp. $[130,136]$.

En cuanto al líquido cefalorraquídeo (LCR), en los pacientes VIH positivos con síntomas neurológicos, la confirmación de tuberculosis, por lo general, requiere de varias sema- 
nas [137]; además, la tinción ácido alcohol resistente tiene una sensibilidad muy baja y la infraestructura para realizar las pruebas moleculares no es viable en muchos países en desarrollo, en los cuales, de manera paradójica, la coinfección es un problema importante de salud pública. Patel y colaboradores $(2010)$ [138,139] compararon la microscopía y la detección de lipoarabinomanano en el líquido cefalorraquídeo de 50 individuos sospechosos de tuberculosis, y hallaron que la prueba para lipoarabinomanano tenía una mejor sensibilidad, pero baja especificidad, lo cual retrasa su aplicación clínica. Por otro lado, la detección de lipoarabinomanano resultó ineficaz en muestras de líquido pleural [140].

En resumen, aunque el ELISA para detección de lipoarabinomanano en diferentes muestras clínicas es una prueba de ejecución rápida y fácil, se debe perfeccionar para que pueda contribuir al diagnóstico oportuno de individuos con tuberculosis, especialmente del grupo de pacientes coinfectados con el VIH.

\section{Dimicolato de trehalosa como indicador potencial de tuberculosis}

Mediante cromatografía en capa delgada y análisis por espectrometría de masas (MALDI-TOF), Fujita y colaboradores (2005) [141] analizaron los ácidos micólicos esterificados del dimicolato de trehalosa de diferentes especies micobacterianas. Para esto, las cepas de Mycobacterium tuberculosis, Mycobacterium bovis, Mycobacterium phlei, Mycobacterium flavescens, Mycobacterium kansaii y del grupo de Mycobacterium avium-intracellulare se trataron en autoclave a $121^{\circ} \mathrm{C}$ durante 15 minutos; después, los lípidos se extrajeron con cloroformo/metanol y la fase orgánica se recuperó y evaporó en un evaporador rotatorio. Los lípidos solubles en acetona y en cloroformo se fraccionaron por cromatografía en capa delgada con un solvente de cloroformo/metanol/agua/ácido acético o de cloroformo/metanol/acetona. El dimicolato de trehalosa se sometió a varias cromatografías en capa delgada, se purificó de los platos de sílica y luego se disolvió en cloroformo/metanol (2:1, v/v).

Los resultados de este estudio mostraron que la combinación y la longitud de las cadenas hidrocarbonadas de los ácidos micólicos pertenecientes al dimicolato de trehalosa eran diferentes en las especies de micobacterias estudiadas, de acuerdo con la producción de diferentes iones de masa que permitió su diferenciación. Aunque el objetivo del estudio era comparar la estructura del dimicolato de trehalosa en diferentes especies de micobacterias, los resultados proporcionaron evidencia de la posibilidad de diferenciar entre el dimicolato de trehalosa de las micobacterias de crecimiento lento y de las de crecimiento rápido, lo cual permitió postularlo como un blanco potencial para el desarrollo de pruebas diagnósticas [141].

\section{Métodos cromatográfi- cos en el diagnóstico de tuberculosis}

La alta sensibilidad de los métodos cromatográficos los convierte en procedimientos atractivos para detectar y cuantificar directamente los metabolitos de Mycobacterium tuberculosis en muestras clínicas. Desde su origen en 1903, la cromatografía ha tenido un progreso enorme que ha permitido realizar análisis más detallados y eficientes $[142,143]$. En el caso de la tuberculosis, diferentes variaciones de la técnica se han utilizado para detectar diversos lípidos de 
la pared micobacteriana, útiles para el diagnóstico de la enfermedad.-

\section{Cromatografía de gases}

El primer informe sobre el uso de la cromatografía de gases fue publicado por James y Martin en 1952 [144,145], aunque su fundamento ya había sido utilizado por Martin y Synge en 1941 [146]. El principio básico de esta técnica comprende la volatilización de la muestra en un inyector a altas temperaturas, la separación de los componentes en una matriz especial y la evidencia de cada uno de ellos mediante un sistema detector. Una característica importante de la cromatografía de gases es el uso de un gas (helio o hidrógeno) como transportador (fase móvil) para transferir la muestra desde el inyector, a través de la matriz, hasta el detector. Un aspecto importante a considerar, es que los materiales adecuados para este tipo de análisis son aquellos que pueden ser volatilizados sin descomponerse $[144,145]$.

La cromatografía de gases ha sido utilizada para la detección de derivados micobacterianos en muestras clínicas, para lo que se requiere de una preparación adecuada de las muestras antes de que sean inyectadas en el cromatógrafo. Dado que los lípidos de la pared celular de la micobacteria están unidos covalentemente a otros lípidos o proteínas, el primer paso es su extracción. Los solventes no polares como el hexano y el éter de petróleo se pueden utilizar en la extracción de lípidos neutrales como los ésteres de ácidos grasos y los acilgliceroles [147]; los lípidos más complejos y más polares como los fosfolípidos, las lipoproteínas y los glicolípidos requieren de solventes más polares como el metanol o el acetonitrilo [148]. Después, los lípidos libres extraídos son derivatizados para ob- tener ésteres metílicos de ácidos grasos mediante la adición de una mezcla de benceno-metanol-ácido sulfúrico $\left(\mathrm{H}_{2} \mathrm{SO}_{4}\right)$ concentrado o $\mathrm{HCl}$ al 3\% en metanol y, luego, de hexano para recolectar la fase orgánica.

\section{Detección e identificación}

\section{de micobacterias}

Ohashi y colaboradores (1977) [149] utilizaron un cromatógrafo de gases con detector de ionización de flama (GC/FID) para analizar cultivos de 32 cepas micobacterias, a partir de los cuales se diferenciaron ocho especies: Mycobacterium flavescens, Mycobacterium fostuitum, Mycobacterium kansaii, Mycobacterium intracellulare, Mycobacterium phlei, Mycobacterium triviale, Mycobacterium vacca y Mycobacterium tuberculosis. En ocho cepas de Mycobacterium tuberculosis se observó una señal a los 5.400 segundos que no se detectó en las 24 cepas restantes; $\sin$ embargo, esta señal no fue identificada. Por su parte, las cepas de las otras siete especies de micobacterias presentaron características específicas en los perfiles cromatográficos.

Larson y colaboradores (1985) [150] también pudieron diferenciar, mediante cromatografía de gases, cuatro aislados clínicos de Mycobacterium tuberculosis, además de la cepa de referencia H37Rv, de cuatro cepas de Mycobacterium bovis, dos de Mycobacterium kansaii y una de Mycobacterium avium, cultivadas en medio líquido. Los cromatogramas de los lisados metanolizados de Mycobacterium tuberculosis y Mycobacterium bovis fueron similares, aunque presentaron diferencias en la proporción de las señales.

Los anteriores resultados, en conjunto, indican que varias especies de micobacterias tienen diferencias inherentes a su composición 
química, lo cual favorece su identificación por cromatografía de gases.

\section{Detección de compuestos volátiles orgánicos en exhalados respiratorios}

El análisis clínico de marcadores volátiles en exhalados respiratorios es atractivo debido a que la recolección de la muestra es un procedimiento no invasivo, fácil, rápido, que se puede repetir las veces que sea necesario y que permite el estudio de procesos bioquímicos que ocurren en el organismo [151]. El análisis moderno del exhalado respiratorio comenzó en 1971, cuando Pauling y colaboradores identificaron más de 200 compuestos en estas muestras usando cromatografía de gases [152,153]. Hoy en día, y gracias al avance tecnológico de los métodos analíticos, más de 3.000 componentes de los exhalados respiratorios han sido separados $y$, por lo menos, 500 identificados, los cuales se han correlacionado con procesos bioquímicos que ocurren en el organismo en condiciones de salud y enfermedad [154].

En el caso particular de la tuberculosis se han realizado algunos estudios, aún preliminares, con resultados que proponen la detección de compuestos volátiles orgánicos en los exhalados respiratorios como una prueba diagnóstica de la infección [155-158]. Syhre y colaboradores (2008 y 2009) detectaron los compuestos volátiles TB5 y TB7 como específicos de cultivos in vitro de Mycobacterium tuberculosis y Mycobacterium bovis [97,159], los cuales se evidenciaron en tres tipos de medios de cultivo (Lowenstein-Jensen-glicerol, agar de sangre de oveja y BacT/Alert líquido) y estuvieron ausentes en los cultivos del complejo Mycobacterium avium, Mycobacterium fortuitum, Mycobacterium chelonae,
Mycobacterium abscessus, Aspergillus fumigatus, Aspergillus flavus, Aspergillus niger, Candida albicans y otros patógenos respiratorios (revisado en [155]). Es interesante considerar que estos compuestos puedan ser detectados en los exhalados respiratorios de pacientes con tuberculosis, pero en el momento aún se está a la espera de su verificación.

Phillips y colaboradores (2007) [96], por medio de cromatografía de gases, analizaron y compararon los compuestos volátiles orgánicos producidos en cultivos in vitro de Mycobacterium tuberculosis H37Rv y en exhalados respiratorios de 42 pacientes hospitalizados con sospecha de tuberculosis y 59 individuos sanos pareados por edad. Mediante un análisis multivariado para el reconocimiento de patrones, los autores lograron diferenciar los pacientes hospitalizados de los individuos sanos a través de marcadores de estrés oxidativo, como los alcanos de C4-C20 y sus derivados monometilados, que estaban aumentados en los pacientes $[95,96]$.

Igualmente, los autores en mención, en el grupo de los pacientes hospitalizados con sospecha de tuberculosis pulmonar $(n=42)$ encontraron que los cultivos de esputo fueron positivos para Mycobacterium tuberculosis en 23 de ellos y negativos en 19. Luego, empleando 12 componentes principales del total de 134 compuestos volátiles examinados en el aliento, se identificaron en el análisis de reconocimiento de patrones a los pacientes con cultivos de esputo positivos con una sensibilidad del $82,6 \%(19 / 23)$ y una especificidad del $100 \%$ (18/18). Los compuestos volátiles orgánicos en las muestras de esputo que permitieron la identificación de los pacientes con cultivo positivo eran estructuralmente similares a los compues- 
tos volátiles orgánicos más abundantes, que fueron observados solo en las muestras de los cultivos de Mycobacterium tuberculosis [96].

Tres años después, utilizando la misma tecnología, pero esta vez con análisis de Monte Carlo, se estudiaron 226 individuos sospechosos de tuberculosis por criterios clínicos. El análisis de los compuestos volátiles orgánicos de los exhalados respiratorios para diagnóstico de los individuos tuvo una sensibilidad del $84 \%$ y una especificidad del $64,7 \%$, en comparación con los cultivos de esputo, microscopía directa, radiografías de tórax y sospecha clínica [95].

La tecnología de cromatografía de gases acoplada a masas (GC/MS) utilizada en los estudios anteriores es robusta, costosa y en algunos países no se dispone de ella. Por su parte, la cromatografía de gases con detector de superficie de onda acústica es un enfoque instrumental que atrapa y concentra compuestos volátiles antes de que sean eluídos para ser separados en una corta columna cromatográfica y detectados con la superficie de onda acústica. Esta tecnología permite separar y analizar compuestos volátiles en pocos segundos [160] y ha sido utilizada en diferentes estudios para detectar compuestos volátiles en sustancias vegetales y para monitorear compuestos aromáticos en frutas y flores [161-163]; estudios que han indicado que tiene las ventajas de simplicidad, rapidez de análisis y menor costo en comparación con la cromatografía de gases acoplada a masas.

Phillips y colaboradores (2012) [94] detectaron y analizaron los compuestos volátiles orgánicos en exhalados respiratorios de 251 individuos (130 con tuberculosis pulmonar activa y 121 controles sanos) por medio de cromatografía de gases con detector de superficie de onda acústica en seis minutos por cada prueba. Los análisis identificaron a los pacientes con tuberculosis activa con una sensibilidad del $71,2 \%$ y una especificidad del $71,0 \%$. Aunque la sensibilidad y la especificidad fueron inferiores a los dos reportes del 2007 y del 2010 que usaban esta técnica $[95,96]$, este estudio piloto implementó una prueba que es rápida de realizar y a un menor costo, que puede ser utilizada en laboratorios con escasa infraestructura. Es evidente que la prueba necesita perfeccionarse; sin embargo, es indudable su potencial en el diagnóstico de la tuberculosis.

En nuestro grupo de investigación (Grupo de Inmunología Celular e Inmunogenética GICIG) hemos utilizado otros componentes no volátiles en los exhalados respiratorios recolectados utilizando los denominados «tubos R» (véase figura 9) que han permitido diferenciar, por medio de cromatografía de gases, los pacientes paucibacilares de los pacientes bacilíferos e individuos sanos, con una efectividad del $100 \%$. Entre estos componentes se han encontrado el ácido oleico y la quimioquina CCL-2, lo cual parece ser promisorio para ser usado como un potencial método de diagnóstico [164].

\section{Cromatografía líquida de alta resolución (HPLC)}

En 1985, los científicos en el Centro para el Control y la Prevención de Enfermedades (CDC) propusieron el uso de la cromatografía líquida de alta resolución (HPLC, por sus siglas en inglés) para la clasificación micobacteriana [165]. En 1989, el procedimiento fue incorporado dentro del régimen de pruebas del Centro Nacional de Referencia para Micobacteriología (NRCM, del inglés, The National Reference Centre for Mycobacteriology), agencia de Canadá, y en 1990 

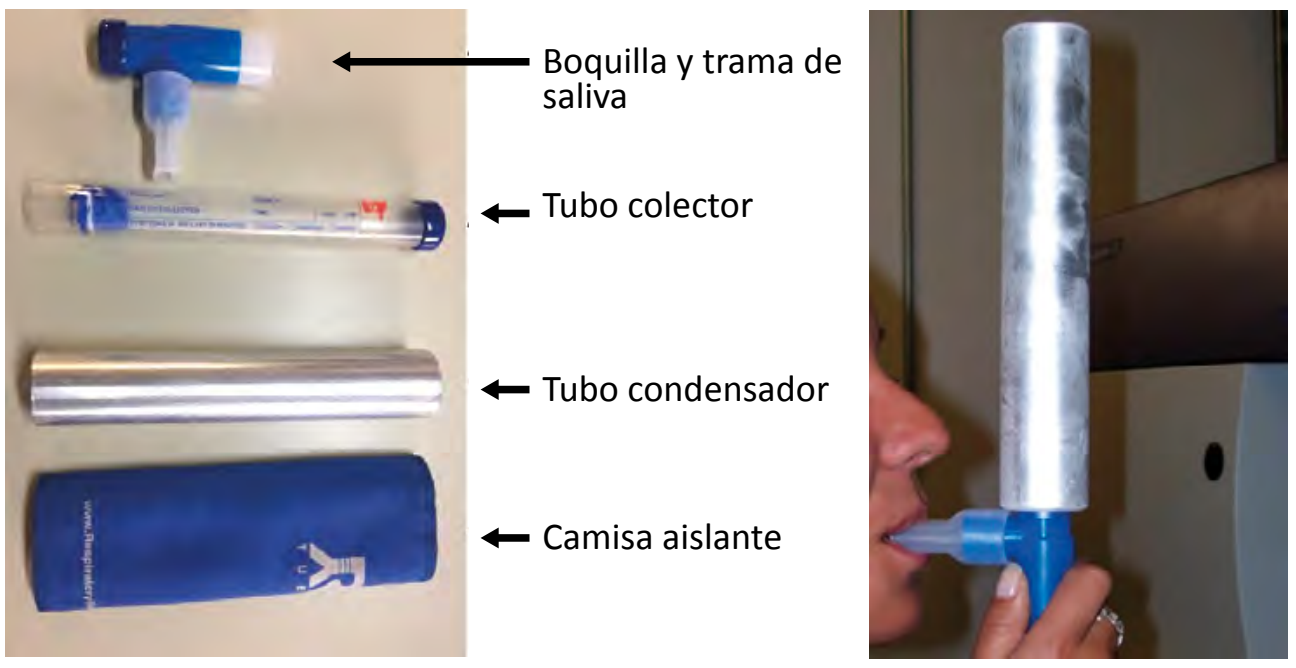

Figura 9. Tubo-R para la obtención de exhalados respiratorios. El tubo $\mathrm{R}(\mathbf{A})$ consiste en un respirador en el que se recolecta y condensa el vapor de aire exhalado que refleja el ambiente del tracto respiratorio superior. Las muestras condensadas se usan para detectar metabolitos inflamatorios y productos micobacterianos. El tubo condensador se almacena a-20 ${ }^{\circ} \mathrm{C}$ para que al momento de usarse se condense el vapor del aire exhalado. Para su uso (B) la persona debe respirar por la boquilla y trama de saliva por un periodo suficiente hasta que se observe la salida de vapor condensado por la boquilla superior. En este momento, el tubo R se sella y se congela. Posteriormente, se empuja el contenido con un émbolo que está insertado dentro del tubo colector para recoger la muestra condensada.

fue ofrecido como prueba estándar para la identificación de especies de Mycobacterium [166,167]. El análisis por HPLC de los ácidos micólicos para la identificación de especies micobacterianas ofrece resultados en horas, contrario a los métodos convencionales que requieren de semanas [167].

La HPLC es uno de los métodos cromatográficos más ampliamente usados en las técnicas analíticas y hace parte de las cromatografías líquidas, las cuales hacen referencia a cualquier procedimiento cromatográfico en el cual la fase en movimiento es un líquido, a diferencia del gas en movimiento de la cromatografía de gases [168]. La fase móvil es la encargada de separar los componentes de la mezcla que fue inyectada en el cromatógrafo en estado líquido, y que es forzada a eluir por una alta presión a través de una colum- na (matriz) cromatográfica [167,169]. Esta matriz (fase estacionaria) puede ser líquida [170] o sólida [169]. La interacción entre los componentes de la mezcla y la fase móvil y la estacionaria definirá su separación y, luego, los componentes pueden ser visualizados por diferentes detectores $[167,169]$.

\section{Detección cromatográfica de ácidos grasos de micobacterias}

\section{Detección}

\section{por cromatografía en capa fina}

En nuestro grupo de investigación (GICIG) se realizó el análisis de lípidos que contienen manosa, localizados en la pared celular de seis aislados clínicos de micobacterias y cultivadas en medio 7H9. De cada aislado se deslipidaron 
$100 \mathrm{mg}$ de proteínas totales, determinados por ácido bicinconínico, a $37{ }^{\circ} \mathrm{C}$ durante 12 horas, usando $\mathrm{CHCl}_{3}: \mathrm{CH}_{3} \mathrm{OH}(2: 1, \mathrm{v} / \mathrm{v})$, seguido de $\mathrm{CHCl}_{3}: \mathrm{CH}_{3} \mathrm{OH}: \mathrm{H}_{2} \mathrm{O}(10: 10: 3, \mathrm{v} / \mathrm{v} / \mathrm{v})$ durante 12 horas adicionales. Para la cromatografía en capa fina unidimensional se cortaron tiras de $10 \times 20 \mathrm{~cm}$. Las placas se secaron y se atomizaron ligeramente con una solución de ácido sulfúrico concentrado al $10 \%$ en etanol absoluto, $\alpha$-naftol o reactivo Dittmer para evidenciar los lípidos, los glucolípidos o los fosfolípidos totales, respectivamente. Las placas se calentaron a $110{ }^{\circ} \mathrm{C}$ hasta que aparecieron las bandas lipídicas, como se observa en la figura 10. Este hallazgo permitió establecer variaciones inherentes al aislado clínico en el contenido de lipoarabinomanano por unidad de proteína, donde se espera, por ende, desenlaces diferentes durante la infección por Mycobacterium tuberculosis.

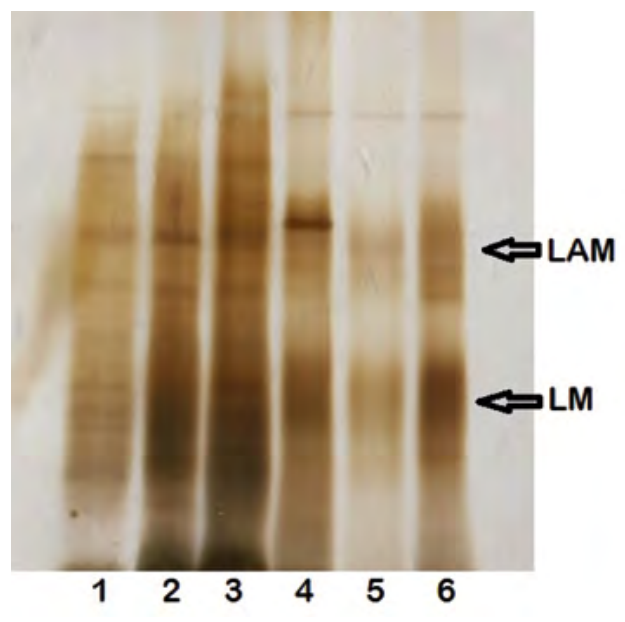

Figura 10. Detección de lipoarabinomanano (LAM) y el lipomanano (LM) por cromatografía de capa fina de seis aislados de micobacterias.

\section{Detección por HPLC}

A partir de cultivos micobacterianos se han detectado y diferenciado cepas de Mycobacterium con base en sus ácidos grasos, los cuales son liberados con hidróxido de potasio en agua-metanol, derivatizados con p-bromofenacil, bicarbonato de sodio y cloroformo y luego inyectados en el cromatógrafo líquido de alta eficacia para su detección [164,171173]. La HPLC también ha sido usada para la detección de ácido tuberculoesteárico en plasma por Traunmuller y colaboradores (2003) [174], quienes detectaron concentraciones más altas de este componente derivatizado con el reactivo fluorescente hidracida ácida 6,7 dimetoxi-1-metil-2(1H)-quinoxalinona-3-propionilcarboxílico (DMEQ-hidracida) en pacientes con tuberculosis activa, que fue confirmada por cultivo ( $n=125)$, en comparación con pacientes con enfermedades pulmonares no tuberculosas $(n=116)$ e individuos sanos $(n=102)$.

De forma adicional, los autores determinaron, en seis pacientes con tuberculosis, las concentraciones de ácido tuberculoesteárico después de seis meses de tratamiento antituberculoso, las cuales fueron estadísticamente menores a las encontradas antes del tratamiento. En el grupo de individuos con enfermedades pulmonares no tuberculosas 14 pacientes con cultivo negativo para Mycobacterium tuberculosis presentaron concentraciones plasmáticas de ácido tuberculoesteárico similares a las del grupo de pacientes con tuberculosis, los cuales se estableciron como falsos positivos. La prueba presentó una sensibilidad del 95,2\%, una especificidad del $87,9 \%$, un valor predictivo positivo del $89,5 \%$ y un valor predictivo negativo del $94,4 \%$, lo que sugiere que es una promisoria herramienta en el diagnóstico rápido y específico de la tuberculosis [174].

En la figura 11 se muestran los espectros de cromatografía líquida-espectrometría de masas (LC/MS) de ácidos micólicos liberados de la pared celular de dos aislados clínicos colombianos de Mycobacterium tu- 


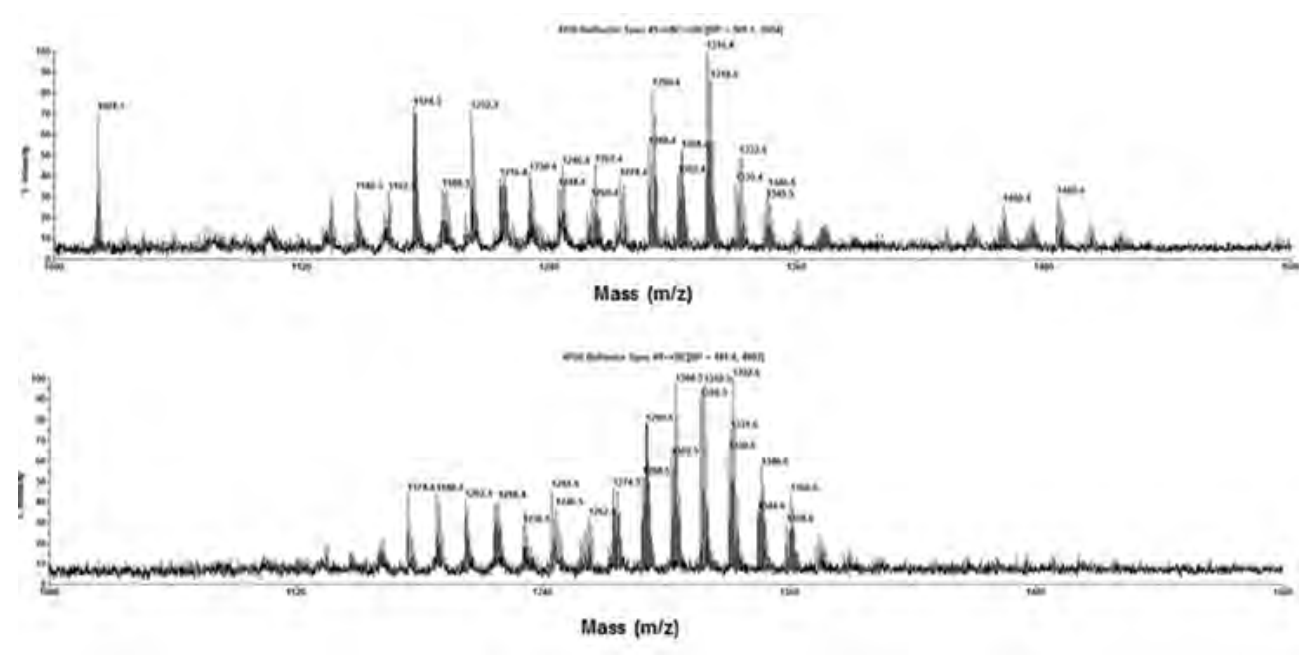

Figura 11. Espectros de masas ( $\mathrm{m} / \mathrm{z}=$ modo negativo de ionización) de ácidos micólicos liberados de la pared celular de dos aislados clínicos colombianos de Mycobacterium tuberculosis, determinados por medio de cromatografía líquida-espectrometría de masas (LC/MS).

berculosis, identificados por nuestro grupo de investigación ( $\mathrm{GICIG})$, donde se aprecian las relaciones carga masa $(\mathrm{m} / \mathrm{z})$ de diferentes variantes del dimicolato de trehalosa y diferentes perfiles de ácidos micólicos, dependiendo del aislado clínico.

\section{Detección por cromatografía de gases}

Diferentes investigaciones han utilizado los ácidos micólicos como moléculas blanco para la detección de Mycobacterium tuberculosis por cromatografía de gases. Los ácidos micólicos fueron definidos por Asselineau y Lederer en 1950 como ácidos grasos hidroxilados, con una larga cadena acilada [175] que puede tener una longitud de 70 a 90 carbonos. Se conocen familias de ácidos micólicos: los micolatos, que no poseen grupos funcionales oxigenados, y los micolatos oxigenados. Las micobacterias patogénas de crecimiento lento, como Mycobacterium tuberculosis, modifican sus ácidos por ciclopropanación, mientras que las micobac- terias de crecimiento rápido, como Mycobacteium smegmatis, no lo hacen [176]. Mycobacterium tuberculosis produce tres clases de ácidos micólicos que difieren principalmente en los sustituyentes que contienen oxígeno en la porción distal de la ramificación del meromicolato [177-179].

Stodola y colaboradores [180] y A. H. Etemadi [181] reportaron que a altas temperaturas $\left(300^{\circ} \mathrm{C}\right)$ las cadenas de carbono de los ácidos micólicos se escinden entre el carbono acilado ramificado y sustituído con un hidroxilo, lo que da lugar a los ésteres metílicos de ácidos grasos. Con base en este principio, Guerrant y colaboradores, en 1981 [168], realizaron extracción de ácidos grasos y metanólisis ácida a cultivos de Mycobacterium tuberculosis H37Rv, Mycobacterium avium, Nocardia (N) caviae, Nocardia asteroides w3315 y Corynebacterium stiatum E2547. Las preparaciones fueron analizadas mediante cromatógrafo de gases con detector de ionización de flama con in- 
yección a $350{ }^{\circ} \mathrm{C}$ para inducir la ruptura de las moléculas de los ácidos micólicos [177179]. El perfil cromatográfico de los ésteres metílicos de ácidos grasos escindidos desde los ácidos micólicos de las nocardias y las corinebacterias tenía menos de 20 átomos de carbono, mientras que los provenientes de micobacterias tenían 20 a 26 y, específicamente, en Mycobacterium tuberculosis H37Rv predominó una señal de 26 carbonos. Cinco años después, el mismo grupo utilizó la cromatografía de gases capilar, técnica que requiere menor cantidad de muestra, y encontraron nuevamente que las señales de las moléculas $\mathrm{C} 26$ son características de Mycobacterium tuberculosis [168].

Kaneda y colaboradores (1986) [182] modificaron el procedimiento de Guerrant y colaboradores, previamente descrito [168], para estabilizar los ácidos micólicos mediante la introducción de un motivo trimetilsilil en el grupo hidroxi en la posición 3, que permitió que la cromatografía de gases se realizar con las moléculas intactas a altas temperaturas, sin que sufrieran pirolisis. Con esta variación estudiaron la estructura y composición de los ácidos micólicos de 25 especies de micobacterias y encontraron que los ácidos micólicos de Mycobacterium bovis y Mycobacterium tuberculosis tienen cadenas hidrocarbonadas más largas que las de otras especies de micobacterias. Este estudio sugiere que los patrones de las subclases de ácidos micólicos de cada especie tienen valor potencial en la clasificación de las micobacterias.

Existen estudios adicionales acerca de la aplicación práctica de la cromatografía de gases de los ésteres metílicos de ácidos grasos en la identificación de las micobacterias. De acuerdo con los perfiles cromatográficos de distintas cepas micobacterianas Tisdall y colaboradores (1979) [183] identificaron 78 de 79 aislados clínicos de micobacterias, en menor tiempo que mediante los métodos bioquímicos. Esta disminución en el tiempo de identificación $(1,5$ h) se debió a que el análisis cromatográfico requiere de menor densidad de crecimiento del bacilo. En el $15 \%$ de los casos de Mycobacterium tuberculosisno fue posible hacer la diferenciación con Mycobacterium bovis y Mycobacterium xenopi, los cuales producen en pocas ocasiones enfermedad en los humanos.

Tres años después, los mismos autores compararon la identificación cromatográfica y bioquímica de 335 aislados clínicos de micobacterias recolectadas durante 10 meses, de los cuales 223 fueron identificados de manera correcta y 95 presentaron perfiles cromatográficos similares. Estos últimos fueron ubicados en dos grupos, uno que incluía a Mycobacterium tuberculosis, Mycobacterium bovis y Mycobacterium xenopi, y otro que incluía a Mycobacterium avium, Mycobacterium scrofulaceum y Mycobacterium gastri. En estos casos, las características morfológicas de las cepas fueron importantes para la identificación final. Los 17 aislados clínicos restantes presentaron perfiles cromatográficos que no se pudieron resolver [184].

La dificultad para diferenciar las especies de Mycobacterium tuberculosis y Mycobacterium xenopi, así como la identidad de $\mathrm{Myco-}$ bacterium avium fueron resueltas por Ozbek y Aktas (2003) mediante los análisis de ésteres metílicos de ácidos grasos, utilizando el programa informático Sherlock Microbial Identification System (MIS) versión 4.0 $[148,185]$. Este programa cuenta con una amplia librería de ésteres metílicos de ácidos grasos relacionada con las condiciones de crecimiento del organismo, tales como el 
medio de cultivo y la temperatura utilizada (para mayor información veáse http://www. midi-inc.com/pages/microbial_id.html). El estudió utilizó 61 aislados clínicos y seis cepas de referencia de Mycobacterium tuberculosis, Mycobacterium xenopi y $\mathrm{Myco}$ bacterium avium, cultivadas in vitro, que fueron identificadas de manera correcta con base en la concentración y composición de 12 ácidos grasos de 14 a 20 carbonos de longitud. Mycobacterium tuberculosis se caracterizó por altas concentraciones de los ésteres metílicos de ácidos grasos 16:0, 18:19 y el ácido tuberculoesteárico, y bajas concentraciones de los ésteres metílicos de ácidos grasos 14:0. Por su parte, los ésteres metílicos de ácidos grasos 15:0 y 17:0 fueron detectados de manera exclusiva en Mycobacterium tuberculosis [148].

A pesar de los hallazgos anteriores, en el análisis de los ésteres metílicos de ácidos grasos por cromatografía de gases de diferentes especies micobacterianas, realizado por Luquin y colaboradores (1989) [186], el éster metílico de ácidos grasos 15:0 fue detectado en Mycobacterium xenopi (26 cepas) y Mycobacterium avium (21 cepas); además, en estos últimos no se detectó el éster metílico de ácidos grasos 17:0. De este modo, no es clara la especificidad de estos ésteres metílicos de ácidos grasos para la identificación de Mycobacterium tuberculosis. Por el contrario, y según al menos dos estudios [148,185], el programa Sherlock Microbial Identification System sí ha resultado eficiente y consistente en la identificación y diferenciación de las especies de Mycobacterium.

En un estudio realizado en Cuba, mediante el análisis de los ésteres metílicos de ácidos grasos micobacterianos, se identificaron 29 aislados clínicos obtenidos de cultivos in vi- tro; 25 de ellos provenientes de pacientes inmunocomprometidos. Todos los aislados clínicos presentaron perfiles cromatográficos similares al de la cepa referencia de Mycobacterium tuberculosis H37Rv (14:0, 15:0, $16: 1 \omega 7 c, 16: 1 \omega 6 c, 16: 0,17: 0,18: 2 \omega 6,9 c$, 18:1w9c, 18:0, 10Me-18:0 tuberculosteárico), lo cual confirmó los resultados de los estudios mencionados anteriormente; sin embargo, el éster metílico de ácidos grasos 26:0 fue el más abundante [148].

El inconveniente de los estudios anteriormente descritos es que requieren entre $5 \mathrm{mg}$ y $10 \mathrm{mg}$ de masa bacteriana, es decir, una alta concentración bacilar para realizar los ensayos de identificación; una cantidad que, con escasa probabilidad, se podría obtener directamente de las muestras clínicas.

Por otro lado, la identificación del ácido tuberculoesteárico (ácido 10-metiloctadecanoico), otro lípido de la pared celular micobacteriana, mediante cromatografía de gases, tiene como ventaja que se ha realizado directamente en muestras clínicas para asociarlo con la presencia de Mycobacterium tuberculosis. El ácido tuberculoesteárico es un ácido graso saturado ramificado que contiene un grupo metilo como sustituyente en la cadena hidrocarbonada [187], que fue aislado inicialmente por Anderson y Chargaff (1929) [188] a patir de cepas de Mycobacterium tuberculosis, pero que luego fue demostrado en otras especies del género Mycobacterium y en un número limitado de bacterias del orden Actinomycetales, como las nocardias y las corinebacterias $[130,170,173,189,190]$. Aunque su presencia no es exclusiva de Mycobacterium tuberculosis, las demás bacterias que lo producen no tienen mayor importancia como patógenos humanos, de modo que su detección, junto 
con la clínica del paciente, puede ser de gran ayuda para un diagnóstico rápido y eficiente.

Odham y colaboradores (1979) [190] recolectaron muestras de esputo de seis individuos sospechosos de tuberculosis y las dividieron en cuatro fracciones: dos partes fueron utilizadas para cultivo en medio Lowenstein-Jensen, otra para tinción y microscopía directa, y la restante fue sometida a transesterificación e inyección en cromatógrafo de gases acoplado a un espectrómetro de masas (GC) MS). El espectrómetro de masas fue ajustado de forma que permitiese "monitorear un ion seleccionado" con una relación masa:carga $(\mathrm{m} / \mathrm{z})$ de 312; señal característica del ácido tuberculoesteárico. Las seis muestras de esputo fueron positivas para tuberculosis en el examen de microscopía directa, y cinco de ellas presentaron la señal $\mathrm{m} / \mathrm{z}$ de 312 . Por su parte, los esputos de ocho pacientes con neumonía no tuberculosa fueron negativos para la señal del ácido tuberculoesteárico.

Cinco días después de la siembra de las muestras de esputo en medio Lowenstein-Jensen, cuando aún no se evidenciaba el crecimiento de las colonias micobacterianas, los autores extrajeron muestras a partir de los cultivos para transesterificarlas e inyectarlas en el cromatógrafo de gases acoplado a masas, ya que con esta estrategia se producen menos señales, lo que facilita la interpretación de los resultados. En este caso, las seis muestras tuvieron señales intensas de $\mathrm{m} / \mathrm{z}$ de 312. [143]. Aunque la detección del ácido tuberculoesteárico en cultivos de esputo de cinco días parece un procedimiento novedoso y eficiente, los mismos autores han mostrado que la ionización negativa de la muestra aumenta la sensibilidad en la detección de la señal del ácido tuberculoesteárico, lo que hace innecesario realizar el cultivo del esputo. Es importante destacar que las muestras de es- puto negativas para Mycobacterium tuberculosis, en el examen directo, pero positivas en el cultivo, presentaron la señal del ácido tuberculoesteárico en la muestra de esputo procesada en forma directa [191].

Al analizar el esputo de un número mayor de pacientes con tuberculosis pulmonar $(n=29)$ se encontró que todos mostraban la señal correspondiente al ácido tuberculoesteárico [143]. Además, el ácido tuberculoesteárico también se detectó en el esputo de 3 de 11 individuos con diagnóstico inicial de enfermedad pulmonar no tuberculosa, en los que el seguimiento y otros exámenes realizados confirmó el diagnóstico de tuberculosis pulmonar [191-193].

En los últimos años se han reportado diversas modificaciones en el proceso de extracción o metilación del ácido tuberculoesteárico para su posterior detección en muestras clínicas como esputo, e incluso suero, con resultados promisorios para el desarrollo de una prueba diagnóstica más rápida y eficiente [171,192].

Por medio de la cromatografía de gases, en nuestro grupo de investigación (GICIG) se han determinado algunas alteraciones en los perfiles lipídicos de los sobrenadantes de cultivos de macrófagos derivados de monocitos infectados in vitro con Mycobacterium tuberculosis [194]. Las diferencias de estos perfiles lipídicos entre pacientes e individuos sanos se han podido corroborar para identificar pacientes paucibacilares, fundamentalmente por la mayor presencia de un derivado esterificable de ácido oleico en los exhalados respiratorios.

\section{Conclusiones}

Los pacientes paucibacilares constituyen un grupo de difícil clasificación, que demanda 
el desarrollo e implementación de nuevas herramientas diagnósticas para poder iniciar el tratamiento antituberculoso a tiempo y, de esta forma, evitar el deterioro de su estado de salud y la transmisión del agente etiológico. Las pruebas que se utilizan en la actualidad para el diagnóstico de los individuos paucibacilares son invasivas, incómodas para el paciente y, en muchos casos, sus resultados pueden tardar meses.

El utilizar como blanco antígenos específicos de Mycobacterium tuberculosis, que además son liberados al medio extracelular, ya sea por secreción activa o por la destrucción de la micobacteria, evita depender de la respuesta inmune del paciente para el diagnóstico, que en algunos casos es deficiente y lleva a falsos negativos. Además, por ser estructuralmente específicos de las micobacterias de crecimiento lento, su detección en muestras clínicas, sumada a los signos y síntomas compatibles con tuberculosis, permitiría el inicio rápido del tratamiento, ya que no dependería del resultado de los cultivos en aquellos casos donde no se evidencia la presencia de los bacilos ácido alcohol resistentes en la baciloscopia.

La detección de lipoarabinomanano en diferentes muestras clínicas, en especial la orina, parece ser la mejor ayuda diagnóstica en el momento para individuos paucibacilares con recuentos de linfocitos T CD4 ${ }^{+}$ menores de $200 / \mu \mathrm{L}$. Se necesitan estudios con un mayor número de pacientes y verificar su utilidad en otras poblaciones aún no estudiadas, como en el continente americano, para que sea implementado su uso en la práctica clínica. El dimicolato de trehalosa y los ácidos grasos, como los ácidos micólicos y el ácido tuberculoestárico, son moléculas que, a pesar de encontrarse en bacterias del orden Actinomycetales, son estructural- mente diferentes en las micobacterias de crecimiento lento. La mayoría de estudios referenciados en esta revisión han detectado estos compuestos a partir de cultivos micobacterianos; por eso, el objetivo es mejorar la sensibilidad de estas herramientas para lograr detectar y diferenciar los analitos a partir de muestras clínicas, donde su concentración es mucho menor.

La detección de compuestos volátiles orgánicos en el exhalado respiratorio es una prueba atractiva por la facilidad en la obtención de la muestra y la rapidez del método. Sin embargo, la implementación necesaria para ser realizada obstaculiza su utilización en muchos laboratorios de países con dificultades económicas. Además, es necesario corroborar la eficiencia del método mediante estudios de cohortes con mayor número de pacientes y de diferente ubicación geográfica.

Los adelantos tecnológicos y los avances en el conocimiento de la enfermedad han permitido desarrollar metodologías diagnósticas alternativas en tuberculosis que, a pesar de ser incipientes en el momento, serán la base diagnóstica en un futuro para mejorar la calidad de vida de los pacientes, especialmente de los individuos paucibacilares. Las herramientas que se buscan deben cumplir con las condiciones de especificidad, sensibilidad, eficiencia y, sobre todo, accesibilidad.

\section{Agradecimientos}

Esta revisión se hizo en el marco de la ejecución de los estudios apoyados por COLCIENCIAS: 1115-4592-1439, CODI: 01532 y el Programa de Sostenibilidad de la Universidad de Antioquia. Además, el autor Sergio F. Mosquera-Restrepo recibió una beca de doctorado de COLCIENCIAS. 


\section{Bibliografía}

1. World Health Organization. Global tuberculosis report 2017. Ginebra, Suiza: World Health Organization; 2017.

2. World Health Organization. Tuberculosis data: Tuberculosis country profiles: Financing for TB prevention, diagnosis and treatment: Colombia. 2017. Disponible: http:// www.who.int/tb/country/data. Consultado: dic 2017

3. Brodie D, Schluger NW. The diagnosis of tuberculosis. Clin Chest Med 2005; 26: 247-271, vi.

4. Druszczynska $M$, Kowalewicz-Kulbat $M$, Fol $M$ Wlodarczyk M, Rudnicka W. Latent M. tuberculosis infection--pathogenesis, diagnosis, treatment and prevention strategies. Pol J Microbiol 2012; 61: 3-10.

5. Wilkinson RJ, Zhu X, Wilkinson KA, Lalvani A, Ivanyi J, Pasvol G, et al. $38000 \mathrm{MW}$ antigen-specific major histocompatibility complex class I restricted interferon-gamma-secreting CD8+ T cells in healthy contacts of tuberculosis. Immunology 1998; 95: 585-590.

6. Borgstrom E, Andersen P, Atterfelt F, Julander I, Kallenius $\mathbf{G}$, Maeurer $\mathbf{M}$, et al. Immune responses to ESAT-6 and CFP-10 by FASCIA and multiplex technology for diagnosis of M. tuberculosis infection; IP-10 is a promising marker. PLoS One 2012; 7: e43438.

7. Koul A, Vranckx L, Dhar N, Gohlmann HW, Ozdemir E, Neefs JM, et al. Delayed bactericidal response of Mycobacterium tuberculosis to bedaquiline involves remodelling of bacterial metabolism. Nat Commun 2014; 5: 3369.

8. Vlachaki E, Psathakis K, Tsintiris K, Iliopoulos A. Delayed response to anti-tuberculosis treatment in a patient on infliximab. Respir Med 2005; 99: 648-652.

9. Escobar AL, Coimbra CE, Jr., Camacho LA, Santos RV. Tuberculin reactivity and tuberculosis epidemiology in the Pakaanova (Wari') Indians of Rondonia, south-western Brazilian Amazon. Int J Tuberc Lung Dis 2004; 8: 45-51.

10. Sellam J, Hamdi H, Roy C, Baron G, Lemann M, Puechal $\mathbf{X}$, et al. Comparison of in vitro-specific blood tests with tuberculin skin test for diagnosis of latent tuberculosis before anti-TNF therapy. Ann Rheum Dis 2007; 66: 16101615.

11. Reider RB, Farber SM. Changing Patterns in Chest Dis ease: A Perspective of Two Decades. Dis Chest 1963; 44: 573-586.

12. Lalvani A, Hill AV. Cytotoxic T-lymphocytes against malaria and tuberculosis: from natural immunity to vaccine design. Clin Sci (Lond) 1998; 95: 531-538.

13. von Reyn CF, Williams DE, Horsburgh CR, Jr., Jaeger AS Marsh BJ, Haslov K, et al. Dual skin testing with Mycobacterium avium sensitin and purified protein derivative to discriminate pulmonary disease due to M. avium complex from pulmonary disease due to Mycobacterium tuberculosis. J Infect Dis 1998; 177: 730-736.

14. Black GF, Weir RE, Floyd S, Bliss L, Warndorff DK, Crampin AC, et al. BCG-induced increase in interferon-gamma response to mycobacterial antigens and efficacy of BCG vaccination in Malawi and the UK: two randomised controlled studies. Lancet 2002; 359: 1393-1401.

15. Kwamanga DO, Swai OB, Agwanda R, Githui W. Effect of non-tuberculous Mycobacteria infection on tuberculin results among primary school children in Kenya. East Afr Med J 1995; 72: 222-227.
16. American Thoracic Society, Centers for Disease Control and Prevention. Diagnostic Standards and Classification of Tuberculosis in Adults and Children. Am J Respir Crit Care Med 2000; 161: 19.

17. Dinnes J, Deeks J, Kunst H, Gibson A, Cummins E, Waugh $\mathbf{N}$, et al. A systematic review of rapid diagnostic tests for the detection of tuberculosis infection. Health Technol Assess 2007; 11: 1-196.

18. Mahairas GG, Sabo PJ, Hickey MJ, Singh DC, Stover CK. Molecular analysis of genetic differences between Mycobacterium bovis BCG and virulent $\mathrm{M}$. bovis. J Bacteriol 1996; 178: 1274-1282.

19. Philipp WJ, Nair S, Guglielmi G, Lagranderie M, Gicquel B, Cole ST. Physical mapping of Mycobacterium bovis BCG pasteur reveals differences from the genome map of Mycobacterium tuberculosis H37Rv and from M. bovis. Microbiology 1996; 142 ( Pt 11): 3135-3145.

20. Hsu T, Hingley-Wilson SM, Chen B, Chen M, Dai AZ, Morin PM, et al. The primary mechanism of attenuation of bacillus Calmette-Guerin is a loss of secreted lytic function required for invasion of lung interstitial tissue. Proc Natl Acad Sci U S A 2003; 100: 12420-12425.

21. Ganguly N, Siddiqui I, Sharma P. Role of M. tuberculosis RD-1 region encoded secretory proteins in protective response and virulence. Tuberculosis (Edinb) 2008; 88: 510-517.

22. Tan T, Lee WL, Alexander DC, Grinstein S, Liu J. The ESAT6/CFP-10 secretion system of Mycobacterium marinum modulates phagosome maturation. Cell Microbiol 2006; 8: 1417-1429.

23. Qiao D, Yang BY, Li L, Ma JJ, Zhang XL, Lao SH, et al. ESAT-6- and CFP-10-specific Th1, Th22 and Th17 cells in tuberculous pleurisy may contribute to the local immune response against Mycobacterium tuberculosis infection. Scand J Immunol 2011; 73: 330-337.

24. Meher AK, Lella RK, Sharma C, Arora A. Analysis of complex formation and immune response of CFP-10 and ESAT-6 mutants. Vaccine 2007; 25: 6098-6106.

25. Arend SM, Engelhard AC, Groot G, de Boer K, Andersen $\mathrm{P}$, Ottenhoff $\mathrm{TH}$, et al. Tuberculin skin testing compared with T-cell responses to Mycobacterium tuberculosis-specific and nonspecific antigens for detection of latent infection in persons with recent tuberculosis contact. Clin Diagn Lab Immunol 2001; 8: 1089-1096.

26. Johnson PD, Stuart RL, Grayson ML, Olden D, Clancy A, Ravn P, et al. Tuberculin-purified protein derivativeMPT-64-, and ESAT-6-stimulated gamma interferon responses in medical students before and after Mycobacterium bovis BCG vaccination and in patients with tuberculosis. Clin Diagn Lab Immunol 1999; 6: 934-937.

27. Brock I, Munk ME, Kok-Jensen A, Andersen P. Performance of whole blood IFN-gamma test for tuberculosis diagnosis based on PPD or the specific antigens ESAT-6 and CFP-10. Int J Tuberc Lung Dis 2001; 5: 462-467.

28. Barnes PF. Diagnosing latent tuberculosis infection Turning glitter to gold. Am J Respir Crit Care Med 2004; 170: 5-6.

29. Battaglioli T, Rintiswati N, Martin A, Palupi KR, Bernaerts G, Dwihardiani B, et al. Comparative performance of Thin Layer Agar and Lowenstein-Jensen culture for diagnosis of tuberculosis. Clin Microbiol Infect 2013; 19: E502-508.

30. Pathan AA, Wilkinson $K A$, Klenerman $\mathbf{P}$, McShane $\mathbf{H}$, 
Davidson RN, Pasvol G, et al. Direct ex vivo analysis of antigen-specific IFN-gamma-secreting CD4 T cells in Mycobacterium tuberculosis-infected individuals: associations with clinical disease state and effect of treatment. J Immunol 2001; 167: 5217-5225.

31. Bishop PJ, Neumann G. The history of the Ziehl-Neelsen stain. Tubercle 1970; 51: 196-206.

32. Mathew P, Kuo YH, Vazirani B, Eng RH, Weinstein MP. Are three sputum acid-fast bacillus smears necessary for discontinuing tuberculosis isolation? J Clin Microbiol 2002; 40: 3482-3484.

33. Hensler NM, Spivey CG, Jr., Dees TM. The use of hypertonic aerosol in production of sputum for diagnosis of tuberculosis. Comparison with gastric specimens. Dis Chest 1961; 40: 639-642.

34. Davies PD, Pai M. The diagnosis and misdiagnosis of tuberculosis. Int J Tuberc Lung Dis 2008; 12: 1226-1234.

35. Dalovisio JR, Montenegro-James S, Kemmerly SA, Genre CF, Chambers R, Greer D, et al. Comparison of the amplified Mycobacterium tuberculosis (MTB) direct test, Amplicor MTB PCR, and IS6110-PCR for detection of MTB in respiratory specimens. Clin Infect Dis 1996; 23: 10991106; discussion 1107-1098.

36. Bergmann JS, Yuoh G, Fish G, Woods GL. Clinical evaluation of the enhanced Gen-Probe Amplified Mycobacterium Tuberculosis Direct Test for rapid diagnosis of tuberculosis in prison inmates. J Clin Microbiol 1999; 37: 1419-1425.

37. Johansen IS, Thomsen VO, Johansen A, Andersen P, Lundgren B. Evaluation of a new commercial assay for diagnosis of pulmonary and nonpulmonary tuberculosis. Eur J Clin Microbiol Infect Dis 2002; 21: 455-460.

38. Mederos LM, Quinones Y, Ruiz A, Teja I, Valdivia JA. [A chromatographic analysis of the Mycobacterium tuberculosis strains isolated from an outbreak in HIV patients in Cuba]. Rev Cubana Med Trop 1998; 50: 120-123.

39. Steingart KR, Flores LL, Dendukuri N, Schiller I, Laal S, Ramsay A, et al. Commercial serological tests for the diagnosis of active pulmonary and extrapulmonary tuberculosis: an updated systematic review and meta-analysis. PLoS Med 2011; 8: e1001062.

40. Flores LL, Steingart KR, Dendukuri N, Schiller I, Minion J, Pai M, et al. Systematic review and meta-analysis of antigen detection tests for the diagnosis of tuberculosis. Clin Vaccine Immunol 2011; 18: 1616-1627.

41. Ling DI, Flores LL, Riley LW, Pai M. Commercial nucleic-acid amplification tests for diagnosis of pulmonary tuberculosis in respiratory specimens: meta-analysis and meta-regression. PLoS One 2008; 3: e1536.

42. Flores LL, Pai M, Colford JM, Jr., Riley LW. In-house nucleic acid amplification tests for the detection of Mycobacterium tuberculosis in sputum specimens: meta-analysis and meta-regression. BMC Microbiol 2005; 5: 55.

43. Morgan M, Kalantri S, Flores L, Pai M. A commercial line probe assay for the rapid detection of rifampicin resistance in Mycobacterium tuberculosis: a systematic review and meta-analysis. BMC Infect Dis 2005; 5: 62.

44. Abdelhaleem AA, Hershan AA, Agarwal PK. Diagnostic Accuracy of IS6110 Insertion Gene, Hsp65, and Xpert MTB/RIF for Rapid Diagnosis of Pulmonary Tuberculosis. JTR 2017; 5: 1-12.

45. Nelson LJ, Wells CD. Global epidemiology of childhood tuberculosis. Int J Tuberc Lung Dis 2004; 8: 636-647.

46. Nelson LJ, Schneider E, Wells CD, Moore M. Epidemiology of childhood tuberculosis in the United States, 19932001: the need for continued vigilance. Pediatrics 2004; 114: 333-341.

47. Lopez Avalos GG, Prado Montes de Oca E. Classic and new diagnostic approaches to childhood tuberculosis. J Trop Med 2012; 2012: 818219 .

48. World Health Organization. International standards for tuberculosis care. Wkly Epidemiol Rec 2006; 81: 43-47.

49. Hopewell PC, Fair EL, Uplekar M. Updating the International Standards for Tuberculosis Care. Entering the era of molecular diagnostics. Ann Am Thorac Soc 2014; 11: 277-285.

50. Lewinsohn DA, Gennaro ML, Scholvinck L, Lewinsohn DM. Tuberculosis immunology in children: diagnostic and therapeutic challenges and opportunities. Int J Tuberc Lung Dis 2004; 8: 658-674.

51. Newton SM, Brent AJ, Anderson S, Whittaker E, Kampmann B. Paediatric tuberculosis. Lancet Infect Dis 2008; 8: 498-510.

52. Marais BJ, Gie RP, Hesseling AC, Schaaf HS, Lombard C, Enarson DA, et al. A refined symptom-based approach to diagnose pulmonary tuberculosis in children. Pediatrics 2006; 118: e1350-1359.

53. Imaz MS, Comini MA, Zerbini E, Sequeira MD, Spoletti MJ, Etchart AA, et al. Evaluation of the diagnostic value of measuring IgG, IgM and IgA antibodies to the recombinant 16-kilodalton antigen of mycobacterium tuberculosis in childhood tuberculosis. Int J Tuberc Lung Dis 2001; 5: 1036-1043.

54. Nicol MP, Pienaar D, Wood K, Eley B, Wilkinson RJ, Henderson $\mathbf{H}$, et al. Enzyme-linked immunospot assay responses to early secretory antigenic target 6 , culture filtrate protein 10 , and purified protein derivative among children with tuberculosis: implications for diagnosis and monitoring of therapy. Clin Infect Dis 2005; 40: 13011308.

55. Hesseling AC, Gie RP. Scoring systems for the diagnosis of childhood tuberculosis: are we making progress? Int J Tuberc Lung Dis 2007; 11: 245.

56. Gomez-Pastrana D, Torronteras R, Caro P, Anguita ML, Lopez-Barrio AM, Andres A, et al. Comparison of amplicor, in-house polymerase chain reaction, and conventional culture for the diagnosis of tuberculosis in children. Clin Infect Dis 2001; 32: 17-22.

57. Khan EA, Starke JR. Diagnosis of tuberculosis in children: increased need for better methods. Emerg Infect Dis 1995; 1: 115-123.

58. World Health Organization. Guidance for national tuberculosis programmes on the management of tuberculosis in children (ed 2a). Ginebra, Suiza: WHO Press; 2014.

59. Zumla A, Schaaf HS. Tuberculosis. Preface. Clin Chest Med 2009; 30: xiii-xviii.

60. Perez-Velez CM, Marais BJ. Tuberculosis in children. N Engl J Med 2012; 367: 348-361.

61. Triasih R, Rutherford M, Lestari T, Utarini A, Robertson CF, Graham SM. Contact investigation of children exposed to tuberculosis in South East Asia: a systematic review. J Trop Med 2012; 2012: 301808.

62. Graham SM. Missed opportunities for prevention of tuberculosis in children. Ann Trop Paediatr 2011; 31: 297 - 
299.

63. Hill PC, Rutherford ME, Audas R, van Crevel R, Graham SM. Closing the policy-practice gap in the management of child contacts of tuberculosis cases in developing countries. PLoS Med 2011; 8: e1001105.

64. Hesseling AC, Graham SM, Cuevas LE. Rapid molecular detection of tuberculosis. N Engl J Med 2011; 364: 183184; author reply 184-185.

65. Graham SM. The use of diagnostic systems for tuberculosis in children. Indian J Pediatr 2011; 78: 334-339.

66. Van Rie A, Page-Shipp L, Scott L, Sanne I, Stevens W. Xpert((R)) MTB/RIF for point-of-care diagnosis of TB in high-HIV burden, resource-limited countries: hype or hope? Expert Rev Mol Diagn 2010; 10: 937-946.

67. Blakemore R, Story E, Helb D, Kop J, Banada P, Owens $M R$, et al. Evaluation of the analytical performance of the Xpert MTB/RIF assay. J Clin Microbiol 2010; 48: 24952501.

68. Helb D, Jones M, Story E, Boehme C, Wallace E, Ho K, et al. Rapid detection of Mycobacterium tuberculosis and rifampin resistance by use of on-demand, near-patient technology. J Clin Microbiol 2010; 48: 229-237.

69. Steingart KR, Sohn H, Schiller I, Kloda LA, Boehme CC, Pai $\mathbf{M}$, et al. Xpert(R) MTB/RIF assay for pulmonary tuberculosis and rifampicin resistance in adults. Cochrane Database Syst Rev 2013; 1: CD009593.

70. Horne DJ, Pinto LM, Arentz M, Lin SY, Desmond E, Flores LL, et al. Diagnostic accuracy and reproducibility of WHO-endorsed phenotypic drug susceptibility testing methods for first-line and second-line antituberculosis drugs. J Clin Microbiol 2013; 51: 393-401.

71. Davis JL, Cattamanchi A, Cuevas LE, Hopewell PC, Steingart KR. Diagnostic accuracy of same-day microscopy versus standard microscopy for pulmonary tuberculosis: a systematic review and meta-analysis. Lancet Infect Dis 2013; 13: 147-154.

72. Boehme CC, Nabeta P, Hillemann D, Nicol MP, Shenai S, Krapp F, et al. Rapid molecular detection of tuberculosis and rifampin resistance. N Engl J Med 2010; 363: 10051015.

73. Shinnick TM, Good RC. Diagnostic mycobacteriology laboratory practices. Clin Infect Dis 1995; 21: 291-299.

74. Li LM, Bai LQ, Yang HL, Xiao CF, Tang RY, Chen YF, et al. Sputum induction to improve the diagnostic yield in patients with suspected pulmonary tuberculosis. Int J Tuberc Lung Dis 1999; 3: 1137-1139.

75. Parry CM, Kamoto O, Harries AD, Wirima JJ, Nyirenda CM, Nyangulu DS, et al. The use of sputum induction for establishing a diagnosis in patients with suspected pulmonary tuberculosis in Malawi. Tuber Lung Dis 1995; 76: 72-76.

76. Hartung TK, Maulu A, Nash J, Fredlund VG. Suspected pulmonary tuberculosis in rural South Africa--sputum induction as a simple diagnostic tool? S Afr Med J 2002; 92: 455-458.

77. Abadco DL, Steiner P. Gastric lavage is better than bronchoalveolar lavage for isolation of Mycobacterium tuberculosis in childhood pulmonary tuberculosis. Pediatr Infect Dis J 1992; 11: 735-738.

78. Pomputius WF, 3rd, Rost J, Dennehy PH, Carter EJ. Standardization of gastric aspirate technique improves yield in the diagnosis of tuberculosis in children. Pediatr Infect
Dis J 1997; 16: 222-226.

79. Connett GJ. Bronchoalveolar lavage. Paediatr Respir Rev 2000; 1: 52-56.

80. Wainwright CE, Grimwood K, Carlin JB, Vidmar S, Cooper PJ, Francis PW, et al. Safety of bronchoalveolar lavage in young children with cystic fibrosis. Pediatr Pulmonol 2008; 43: 965-972.

81. de Gracia J, Curull V, Vidal R, Riba A, Orriols R, Martin $\mathbf{N}$, et al. Diagnostic value of bronchoalveolar lavage in suspected pulmonary tuberculosis. Chest 1988; 93: 329332.

82. Grange JM, Stanford JL, Beck JS. Lymphocyte and lymphocyte subset numbers in blood and bronchoalveolar lavage and pleural fluid in various forms of human pulmonary tuberculosis. Thorax 1992; 47: 1085-1086.

83. Chan HS, Sun AJ, Hoheisel GB. Bronchoscopic aspiration and bronchoalveolar lavage in the diagnosis of sputum smear-negative pulmonary tuberculosis. Lung 1990; 168: 215-220.

84. Liam CK, Chen YC, Yap SF, Srinivas P, Poi PJ. Detection of Mycobacterium tuberculosis in bronchoalveolar lavage from patients with sputum smear-negative pulmonary tuberculosis using a polymerase chain reaction assay. Respirology 1998; 3: 125-129.

85. Chow F, Espiritu N, Gilman RH, Gutierrez R, Lopez S, Escombe AR, et al. La cuerda dulce--a tolerability and acceptability study of a novel approach to specimen collection for diagnosis of paediatric pulmonary tuberculosis. BMC Infect Dis 2006; 6: 67.

86. Beatty WL, Rhoades ER, Ullrich HJ, Chatterjee D, Heuser JE, Russell DG. Trafficking and release of mycobacterial lipids from infected macrophages. Traffic 2000; 1: 235247.

87. Beatty WL, Ullrich HJ, Russell DG. Mycobacterial surface moieties are released from infected macrophages by a constitutive exocytic event. Eur J Cell Biol 2001; 80: 3140.

88. Rhoades E, Hsu F, Torrelles JB, Turk J, Chatterjee D, Russell DG. Identification and macrophage-activating activity of glycolipids released from intracellular Mycobacterium bovis BCG. Mol Microbiol 2003; 48: 875-888.

89. Bhatnagar S, Schorey JS. Exosomes released from infected macrophages contain Mycobacterium avium glycopeptidolipids and are proinflammatory. J Biol Chem 2007; 282: 25779-25789.

90. Harth G, Horwitz MA, Tabatadze D, Zamecnik PC. Targeting the Mycobacterium tuberculosis 30/32-kDa mycolyl transferase complex as a therapeutic strategy against tuberculosis: Proof of principle by using antisense technology. Proc Natl Acad Sci U S A 2002; 99: 15614-15619.

91. Braunstein M, Espinosa BJ, Chan J, Belisle JT, Jacobs WR, Jr. SecA2 functions in the secretion of superoxide dismutase $A$ and in the virulence of Mycobacterium tuberculosis. Mol Microbiol 2003; 48: 453-464.

92. de Jonge MI, Pehau-Arnaudet G, Fretz MM, Romain F, Bottai D, Brodin P, et al. ESAT-6 from Mycobacterium tuberculosis dissociates from its putative chaperone CFP10 under acidic conditions and exhibits membrane-lysing activity. J Bacteriol 2007; 189: 6028-6034.

93. Samuel LP, Song CH, Wei J, Roberts EA, Dahl JL, Barry CE, 3rd, et al. Expression, production and release of the Eis protein by Mycobacterium tuberculosis during infection 
of macrophages and its effect on cytokine secretion. Microbiology 2007; 153: 529-540.

94. Phillips M, Basa-Dalay V, Blais J, Bothamley G, Chaturvedi $A$, Modi KD, et al. Point-of-care breath test for biomarkers of active pulmonary tuberculosis. Tuberculosis (Edinb) 2012; 92: 314-320.

95. Phillips M, Basa-Dalay V, Bothamley G, Cataneo RN, Lam PK, Natividad MP, et al. Breath biomarkers of active pulmonary tuberculosis. Tuberculosis (Edinb) 2010; 90: 145-151.

96. Phillips M, Cataneo RN, Condos R, Ring Erickson GA, Greenberg J, La Bombardi V, et al. Volatile biomarkers of pulmonary tuberculosis in the breath. Tuberculosis (Edinb) 2007; 87: 44-52.

97. Syhre M, Manning L, Phuanukoonnon S, Harino P, Chambers ST. The scent of Mycobacterium tuberculosis-part II breath. Tuberculosis (Edinb) 2009; 89: 263-266.

98. Bhatnagar S, Shinagawa K, Castellino FJ, Schorey JS. Exosomes released from macrophages infected with intracellular pathogens stimulate a proinflammatory response in vitro and in vivo. Blood 2007; 110: 3234-3244.

99. Geisel RE, Sakamoto K, Russell DG, Rhoades ER. In vivo activity of released cell wall lipids of Mycobacterium bovis bacillus Calmette-Guerin is due principally to trehalose mycolates. J Immunol 2005; 174: 5007-5015.

100. Guenin-Mace L, Simeone R, Demangel C. Lipids of pathogenic Mycobacteria: contributions to virulence and host immune suppression. Transbound Emerg Dis 2009; 56: 255-268.

101. Abdallah AM, Gey van Pittius NC, Champion PA, Cox J, Luirink J, Vandenbroucke-Grauls CM, et al. Type VII secretion--mycobacteria show the way. Nat Rev Microbiol 2007; 5: 883-891.

102. Driessen NN, Ummels R, Maaskant JJ, Gurcha SS, Besra GS, Ainge GD, et al. Role of phosphatidylinositol mannosides in the interaction between mycobacteria and DCSIGN. Infect Immun 2009; 77: 4538-4547.

103. Mazurek J, Ignatowicz L, Kallenius G, Svenson SB, Pawlowski A, Hamasur B. Divergent effects of mycobacterial cell wall glycolipids on maturation and function of human monocyte-derived dendritic cells. PLoS One 2012; 7: e42515.

104. Vergne I, Fratti RA, Hill PJ, Chua J, Belisle J, Deretic V. Mycobacterium tuberculosis phagosome maturation arrest: mycobacterial phosphatidylinositol analog phosphatidylinositol mannoside stimulates early endosomal fusion. Mol Biol Cell 2004; 15: 751-760.

105. Guerardel $\mathrm{Y}$, Maes E, Elass E, Leroy $\mathrm{Y}$, Timmerman P, Besra GS, et al. Structural study of lipomannan and lipoarabinomannan from Mycobacterium chelonae. Presence of unusual components with alpha 1,3-mannopyranose side chains. J Biol Chem 2002; 277: 30635-30648.

106. Khoo KH, Dell A, Morris HR, Brennan PJ, Chatterjee D. Inositol phosphate capping of the nonreducing termini of lipoarabinomannan from rapidly growing strains of Mycobacterium. J Biol Chem 1995; 270: 12380-12389.

107. Brown MC, Taffet SM. Lipoarabinomannans derived from different strains of Mycobacterium tuberculosis differentially stimulate the activation of NF-kappa B and KBF1 in murine macrophages. Infect Immun 1995; 63: 1960-1968.

108. Mahon RN, Sande OJ, Rojas RE, Levine AD, Harding CV,
Boom WH. Mycobacterium tuberculosis ManLAM inhibits T-cell-receptor signaling by interference with ZAP-70, Lck and LAT phosphorylation. Cell Immunol 2012; 275: 98-105.

109. Rojas M, Garcia LF, Nigou J, Puzo G, Olivier M. Mannosylated lipoarabinomannan antagonizes Mycobacterium tuberculosis-induced macrophage apoptosis by altering Ca+2-dependent cell signaling. J Infect Dis 2000; 182: 240-251.

110. Elbein AD, Pan YT, Pastuszak I, Carroll D. New insights on trehalose: a multifunctional molecule. Glycobiology 2003; 13: 17R-27R.

111. Reither K, Saathoff E, Jung J, Minja LT, Kroidl I, Saad E, et al. Low sensitivity of a urine LAM-ELISA in the diagnosis of pulmonary tuberculosis. BMC Infect Dis 2009; 9: 141.

112. Lopez-Sanchez LM, Jurado-Gamez B, Feu-Collado N, Valverde A, Canas A, Fernandez-Rueda JL, et al. Exhaled breath condensate biomarkers for the early diagnosis of lung cancer using proteomics. Am J Physiol Lung Cell Mol Physiol 2017; 313: L664-L676.

113. Mehta A, Cordero J, Dobersch S, Romero-Olmedo AJ, Savai R, Bodner J, et al. Non-invasive lung cancer diagnosis by detection of GATA6 and NKX2-1 isoforms in exhaled breath condensate. EMBO Mol Med 2016; 8: 13801389.

114. Rozy A, Czerniawska J, Stepniewska A, Wozbinska B, Goljan A, Puscinska E, et al. Inflammatory markers in the exhaled breath condensate of patients with pulmonary sarcoidosis. J Physiol Pharmacol 2006; 57 Suppl 4: 335340.

115. Thomas PS, Lowe AJ, Samarasinghe P, Lodge $\mathrm{CJ}$, Huang $\mathrm{Y}, \mathrm{Abramson} \mathrm{MJ}$, et al. Exhaled breath condensate in pediatric asthma: promising new advance or pouring cold water on a lot of hot air? a systematic review. Pediatr Pulmonol 2013; 48: 419-442.

116. Lawn SD. Point-of-care detection of lipoarabinomannan (LAM) in urine for diagnosis of HIV-associated tuberculosis: a state of the art review. BMC Infect Dis 2012; 12: 103.

117. Hamasur B, Haile M, Pawlowski A, Schroder U, Kallenius G, Svenson SB. A mycobacterial lipoarabinomannan specific monoclonal antibody and its $F\left(a b^{\prime}\right)$ fragment prolong survival of mice infected with Mycobacterium tuberculosis. Clin Exp Immunol 2004; 138: 30-38.

118. Balcha TT, Winqvist N, Sturegard E, Skogmar S, Reepalu A, Jemal $\mathbf{Z H}$, et al. Detection of lipoarabinomannan in urine for identification of active tuberculosis among HIV-positive adults in Ethiopian health centres. Trop Med Int Health 2014; 19: 734-742.

119. Boehme C, Molokova E, Minja F, Geis S, Loscher T, Maboko L, et al. Detection of mycobacterial lipoarabinomannan with an antigen-capture ELISA in unprocessed urine of Tanzanian patients with suspected tuberculosis. Trans R Soc Trop Med Hyg 2005; 99: 893-900.

120. Suwanpimolkul G, Kawkitinarong K, Manosuthi W, Sophonphan J, Gatechompol S, Ohata PJ, et al. Utility of urine lipoarabinomannan (LAM) in diagnosing tuberculosis and predicting mortality with and without HIV: prospective TB cohort from the Thailand Big City TB Research Network. Int J Infect Dis 2017; 59: 96-102.

121. Peter J, Green C, Hoelscher M, Mwaba P, Zumla A, Dheda K. Urine for the diagnosis of tuberculosis: current approaches, clinical applicability, and new developments. 
Curr Opin Pulm Med 2010; 16: 262-270.

122. Daley $P$, Michael JS, Hmar $P$, Latha $A$, Chordia $P$, Mathai $D$, et al. Blinded evaluation of commercial urinary lipoarabinomannan for active tuberculosis: a pilot study. Int J Tuberc Lung Dis 2009; 13: 989-995.

123. Mutetwa R, Boehme C, Dimairo M, Bandason T, Munyati SS, Mangwanya D, et al. Diagnostic accuracy of commercial urinary lipoarabinomannan detection in African tuberculosis suspects and patients. Int J Tuberc Lung Dis 2009; 13: 1253-1259.

124. Gupta-Wright A, Peters JA, Flach C, Lawn SD. Detection of lipoarabinomannan (LAM) in urine is an independent predictor of mortality risk in patients receiving treatment for HIV-associated tuberculosis in sub-Saharan Africa: a systematic review and meta-analysis. BMC Med 2016; 14: 53.

125. Peter JG, Theron G, Dheda K. Can point-of-care urine LAM strip testing for tuberculosis add value to clinical decision making in hospitalised HIV-infected persons? PLoS One 2013; 8: e54875.

126. Sabur NF, Esmail A, Brar MS, Dheda K. Diagnosing tuberculosis in hospitalized HIV-infected individuals who cannot produce sputum: is urine lipoarabinomannan testing the answer? BMC Infect Dis 2017; 17: 803.

127. Sahle SN, Asress DT, Tullu KD, Weldemariam AG, Tola $\mathrm{HH}$, Awas YA, et al. Performance of point-of-care urine test in diagnosing tuberculosis suspects with and without HIV infection in selected peripheral health settings of Addis Ababa, Ethiopia. BMC Res Notes 2017; 10: 74.

128. Zijenah LS, Kadzirange G, Bandason T, Chipiti MM, Gwambiwa B, Makoga F, et al. Comparative performance characteristics of the urine lipoarabinomannan strip test and sputum smear microscopy in hospitalized HIVinfected patients with suspected tuberculosis in Harare, Zimbabwe. BMC Infect Dis 2016; 16: 20.

129. Drain PK, Gounder L, Sahid F, Moosa MY. Rapid Urine LAM Testing Improves Diagnosis of Expectorated SmearNegative Pulmonary Tuberculosis in an HIV-endemic Region. Sci Rep 2016; 6: 19992.

130. Dheda K, Davids V, Lenders L, Roberts T, Meldau R, Ling $D$, et al. Clinical utility of a commercial LAM-ELISA assay for TB diagnosis in HIV-infected patients using urine and sputum samples. PLoS One 2010; 5: e9848.

131. Lawn SD, Kerkhoff AD, Burton R, Meintjes G. Underestimation of the incremental diagnostic yield of HIV-associated tuberculosis in studies of the Determine TB-LAM Ag urine assay. AIDS 2014; 28: 1846-1848.

132. Shah M, Variava E, Holmes CB, Coppin A, Golub JE, McCallum J, et al. Diagnostic accuracy of a urine lipoarabinomannan test for tuberculosis in hospitalized patients in a High HIV prevalence setting. J Acquir Immune Defic Syndr 2009; 52: 145-151.

133. Sada E, Brennan PJ, Herrera T, Torres M. Evaluation of lipoarabinomannan for the serological diagnosis of tuberculosis. J Clin Microbiol 1990; 28: 2587-2590.

134. Sada E, Aguilar D, Torres M, Herrera T. Detection of lipoarabinomannan as a diagnostic test for tuberculosis. J Clin Microbiol 1992; 30: 2415-2418.

135. Pereira Arias-Bouda LM, Nguyen LN, Ho LM, Kuijper S, Jansen HM, Kolk AH. Development of antigen detection assay for diagnosis of tuberculosis using sputum samples. J Clin Microbiol 2000; 38: 2278-2283.
136. Dheda K, Van-Zyl Smit RN, Sechi LA, Badri M, Meldau R, Symons G, et al. Clinical diagnostic utility of IP-10 and LAM antigen levels for the diagnosis of tuberculous pleural effusions in a high burden setting. PLoS One 2009; 4: e4689.

137. Sardella IG, Singh M, Kumpfer S, Heringer RR, Saad MH, Sohler MP. Evaluation of Lionex TB kits and mycobacterial antigens for IgG and IgA detection in cerebrospinal fluid from tuberculosis meningitis patients. Mem Inst Oswaldo Cruz 2010; 105: 722-728.

138. Patel VB, Singh R, Connolly C, Coovadia Y, Peer AK, Parag $\mathbf{P}$, et al. Cerebrospinal T-cell responses aid in the diagnosis of tuberculous meningitis in a human immunodeficiency virus- and tuberculosis-endemic population. Am J Respir Crit Care Med 2010; 182: 569-577.

139. Patel VB, Singh R, Connolly C, Kasprowicz V, Zumla A, Ndungu $T$, et al. Comparison of a clinical prediction rule and a LAM antigen-detection assay for the rapid diagnosis of TBM in a high HIV prevalence setting. PLoS One 2010; 5: e15664.

140. Demkow U, Filewska M, Bialas B, Szturmowicz M, Zielonka T, Wesolowski S, et al. [Antimycobacterial antibody level in pleural, pericardial and cerebrospinal fluid of patients with tuberculosis]. Pneumonol Alergol Pol 2004; 72: 105-110.

141. Fujita Y, Naka T, Doi T, Yano I. Direct molecular mass determination of trehalose monomycolate from 11 species of mycobacteria by MALDI-TOF mass spectrometry. Microbiology 2005; 151: 1443-1452.

142. Beccaria M, Mellors TR, Petion JS, Rees CA, Nasir M, Systrom HK, et al. Preliminary investigation of human exhaled breath for tuberculosis diagnosis by multidimensional gas chromatography - Time of flight mass spectrometry and machine learning. J Chromatogr B Analyt Technol Biomed Life Sci 2018; 1074-1075: 46-50.

143. French GL, Chan CY, Cheung SW, Oo KT. Diagnosis of pulmonary tuberculosis by detection of tuberculostearic acid in sputum by using gas chromatography-mass spectrometry with selected ion monitoring. J Infect Dis 1987; 156: 356-362

144. James AT, Martin AJ. Gas-liquid partition chromatography: the separation and micro-estimation of ammonia and the methylamines. Biochem J 1952; 52: 238-242.

145. James AT, Martin AJ. Gas-liquid partition chromatography; the separation and micro-estimation of volatile fatty acids from formic acid to dodecanoic acid. Biochem J 1952; 50: 679-690.

146. Martin AJ, Synge RL. A new form of chromatogram employing two liquid phases: A theory of chromatography. 2. Application to the micro-determination of the higher monoamino-acids in proteins. Biochem J 1941; 35: 13581368.

147. Jackson SK, Stark JM, Taylor S, Harwood JL. Changes in phospholipid fatty acid composition and triacylglycerol content in mouse tissues after infection with bacille Calmette-Guerin. Br J Exp Pathol 1989; 70: 435-441.

148. Ozbek A, Aktas O. Identification of three strains of Mycobacterium species isolated from clinical samples using fatty acid methyl ester profiling. J Int Med Res 2003; 31: 133-140.

149. Ohashi DK, Wade TJ, Mandle RJ. Characterization of ten species of mycobacteria by reaction-gas-liquid chromatography. J Clin Microbiol 1977; 6: 469-473. 
150. Larsson L, Jantzen E, Johnsson J. Gas chromatographic fatty acid profiles for characterisation of mycobacteria: an interlaboratory methodological evaluation. Eur J Clin Microbiol 1985; 4: 483-487.

151. Cepelak I, Dodig S. Exhaled breath condensate: a new method for lung disease diagnosis. Clin Chem Lab Med 2007; 45: 945-952.

152. Teranishi R, Mon TR, Robinson AB, Cary P, Pauling L. Gas chromatography of volatiles from breath and urine. Anal Chem 1972; 44: 18-20.

153. Pauling L, Robinson AB, Teranishi R, Cary P. Quantitative analysis of urine vapor and breath by gas-liquid partition chromatography. Proc Natl Acad Sci U S A 1971; 68: 23742376.

154. Kuban P, Foret F. Exhaled breath condensate: determination of non-volatile compounds and their potential for clinical diagnosis and monitoring. A review. Anal Chim Acta 2013; 805: 1-18.

155. Chambers ST, Scott-Thomas A, Epton M. Developments in novel breath tests for bacterial and fungal pulmonary infection. Curr Opin Pulm Med 2012; 18: 228-232.

156. Nizio KD, Perrault KA, Troobnikoff AN, Ueland M, Shoma S, Iredell JR, et al. In vitro volatile organic compound profiling using GCxGC-TOFMS to differentiate bacteria associated with lung infections: a proof-of-concept study. J Breath Res 2016; 10: 026008.

157. Reinhold P, Kirschvink N, Theegarten D, Berndt A. An experimentally induced Chlamydia suis infection in pigs results in severe lung function disorders and pulmonary inflammation. Vet Res 2008; 39: 35.

158. Yildirim Z, Bozkurt B, Ozol D, Armutcu F, Akgedik R, Karamanli $\mathbf{H}$, et al. Increased Exhaled 8-Isoprostane and Interleukin-6 in Patients with Helicobacter pylori Infection. Helicobacter 2016; 21: 389-394.

159. Syhre M, Chambers ST. The scent of Mycobacterium tuberculosis. Tuberculosis (Edinb) 2008; 88: 317-323.

160. Han D, Wang Z, Cheng J, Wang Q, Chen X, Wang H. Volatile organic compounds (VOCs) during non-haze and haze days in Shanghai: characterization and secondary organic aerosol (SOA) formation. Environ Sci Pollut Res Int 2017; 24: 18619-18629.

161. Hartikainen A, Yli-Pirila P, Tiitta P, Leskinen A, Kortelainen $\mathbf{M}$, Orasche J, et al. Volatile organic compounds from logwood combustion: Emissions and transformation under dark and photochemical aging conditions in a smog chamber. Environ Sci Technol 2018.

162. Holopainen JK, Kivimaenpaa M, Nizkorodov SA. Plant-derived Secondary Organic Material in the Air and Ecosystems. Trends Plant Sci 2017; 22: 744-753.

163. Liu T, Liu Q, Li Z, Huo L, Chan M, Li X, et al. Emission of volatile organic compounds and production of secondary organic aerosol from stir-frying spices. Sci Total Environ 2017; 599-600: 1614-1621.

164. Mosquera-Restrepo SF, Caro AC, Garcia LF, Pelaez-Jaramillo CA, Rojas M. Fatty acid derivative, chemokine, and cytokine profiles in exhaled breath condensates can differentiate adult and children paucibacillary tuberculosis patients. J Breath Res 2017; 11: 016003.

165. Butler WR, Guthertz LS. Mycolic acid analysis by high-performance liquid chromatography for identification of Mycobacterium species. Clin Microbiol Rev 2001; 14: 704-726, table of contents.
166. Levy-Frebault V, Goh KS, David HL. Mycolic acid analysis for clinical identification of Mycobacterium avium and related mycobacteria. J Clin Microbiol 1986; 24: 835-839.

167. Viader-Salvado JM, Molina-Torres CA, Guerrero-Olazaran $M$. Detection and identification of mycobacteria by mycolic acid analysis of sputum specimens and young cultures. J Microbiol Methods 2007; 70: 479-483.

168. Guerrant GO, Lambert MA, Moss CW. Gas-chromatographic analysis of mycolic acid cleavage products in mycobacteria. J Clin Microbiol 1981; 13: 899-907.

169. Leite CQ, da Silva Rocha A, de Andrade Leite SR, Ferreira RM, Suffys PN, de Souza Fonseca L, et al. A comparison of mycolic acid analysis for nontuberculous mycobacteria identification by thin-layer chromatography and molecular methods. Microbiol Immunol 2005; 49: 571-578.

170. Tisdall PA, Anhalt JP. Rapid differentiation of Streptomyces from Nocardia by liquid chromatography. J Clin Microbiol 1979; 10: 503-505.

171. Kaal E, Kolk AH, Kuijper S, Janssen HG. A fast method for the identification of Mycobacterium tuberculosis in sputum and cultures based on thermally assisted hydrolysis and methylation followed by gas chromatography-mass spectrometry. J Chromatogr A 2009; 1216: 6319-6325.

172. Torrelles JB, Sieling PA, Zhang N, Keen MA, McNeil MR, Belisle JT, et al. Isolation of a distinct Mycobacterium tuberculosis mannose-capped lipoarabinomannan isoform responsible for recognition by $\mathrm{CD} 1 \mathrm{~b}$-restricted $\mathrm{T}$ cells. Glycobiology 2012; 22: 1118-1127.

173. Larsson L, Mardh P, Odham G, Westerdahl G. Use of selected ion monitoring for detection of tuberculostearic and C32 mycocerosic acid in mycobacteria and in fiveday-old cultures of sputum specimens from patients with pulmonary tuberculosis. Acta Pathol Microbiol Scand B 1981; 89: 245-251.

174. Traunmuller F, Zeitlinger MA, Stoiser B, Lagler H, Abdel Salam HA, Presterl E, et al. Circulating tuberculostearic acid in tuberculosis patients. Scand J Infect Dis 2003; 35: 790-793.

175. Asselineau J, Lederer E. Structure of the mycolic acids of Mycobacteria. Nature 1950; 166: 782-783.

176. Liu J, Barry CE, 3rd, Besra GS, Nikaido H. Mycolic acid structure determines the fluidity of the mycobacterial cell wall. J Biol Chem 1996; 271: 29545-29551.

177. Dao DN, Sweeney K, Hsu T, Gurcha SS, Nascimento IP, Roshevsky D, et al. Mycolic acid modification by the mmaA4 gene of $M$. tuberculosis modulates IL-12 production. PLoS Pathog 2008; 4: e1000081.

178. Yuan Y, Zhu Y, Crane DD, Barry CE, 3rd. The effect of oxygenated mycolic acid composition on cell wall function and macrophage growth in Mycobacterium tuberculosis. Mol Microbiol 1998; 29: 1449-1458.

179. Minnikin DE, Minnikin SM, Parlett JH, Goodfellow M. Mycolic acid patterns of some rapidly-growing species of Mycobacterium. Zentralbl Bakteriol Mikrobiol Hyg A 1985; 259: 446-460.

180. Stodola FH, Deinema MH, Spencer JF. Extracellular lipids of yeasts. Bacteriol Rev 1967; 31: 194-213.

181. Etemadi AH. [Isolation of Isopentadecanoic and Isoheptadecanoic Acids from the Lipids of Corynebacterium Parvum]. Bull Soc Chim Biol (Paris) 1963; 45: 1423-1432.

182. Kaneda K, Naito S, Imaizumi S, Yano I, Mizuno S, Tomiyasu $\mathrm{I}$, et al. Determination of molecular species com- 
position of $\mathrm{C} 80$ or longer-chain alpha-mycolic acids in Mycobacterium spp. by gas chromatography-mass spectrometry and mass chromatography. J Clin Microbiol 1986; 24: 1060-1070.

183. Tisdall PA, Roberts GD, Anhalt JP. Identification of clinical isolates of mycobacteria with gas-liquid chromatography alone. J Clin Microbiol 1979; 10: 506-514.

184. Tisdall PA, DeYoung DR, Roberts GD, Anhalt JP. Identification of clinical isolates of mycobacteria with gas-liquid chromatography: a 10-month follow-up study. J Clin Microbiol 1982; 16: 400-402.

185. Aktas $\mathrm{O}, \mathrm{Ozbek} A$. Prevalence and in-vitro antimicrobial susceptibility patterns of Acinetobacter strains isolated from patients in intensive care units. J Int Med Res 2003; 31: 272-280.

186. Luquin M, Lopez F, Ausina V. Capillary gas chromatographic analysis of mycolic acid cleavage products, cellular fatty acids, and alcohols of Mycobacterium xenopi. J Clin Microbiol 1989; 27: 1403-1406.

187. Prout FS, Cason J, Ingersoll AW. The synthesis of tuberculostearic acid. J Am Chem Soc 1947; 69: 1233.

188. Anderson $C$. The chemistry of the lipids of the tubercle bacillus. J Biol Chem 1929; 85: 6.

189. Larsson L, Mardh PA, Odham G. Detection of tuberculostearic acid in mycobacteria and nocardiae by gas chromatography and mass spectrometry using selected ion monitoring. J Chromatogr 1979; 163: 221-224.

190. Odham G, Larsson L, Mardh PA. Demonstration of tuberculostearic acid in sputum from patients with pulmonary tuberculosis by selected ion monitoring. J Clin Invest 1979; 63: 813-819.

191. Pang JA, Chan HS, Chan CY, Cheung SW, French GL. A tuberculostearic acid assay in the diagnosis of sputum smear-negative pulmonary tuberculosis. A prospective study of bronchoscopic aspirate and lavage specimens. Ann Intern Med 1989; 111: 650-654.

192. Dang NA, Mourao M, Kuijper S, Walters E, Janssen HG, Kolk AH. Direct detection of Mycobacterium tuberculosis in sputum using combined solid phase extraction-gas chromatography-mass spectrometry. J Chromatogr B Analyt Technol Biomed Life Sci 2015; 986-987: 115-122.

193. Savic B, Sjobring U, Alugupalli S, Larsson L, Miorner H. Evaluation of polymerase chain reaction, tuberculostearic acid analysis, and direct microscopy for the detection of Mycobacterium tuberculosis in sputum. J Infect Dis 1992; 166: 1177-1180.

194. Mosquera-Restrepo SF, Caro AC, Pelaez-Jaramillo CA, Rojas M. Mononuclear phagocyte accumulates a stearic acid derivative during differentiation into macrophages. Effects of stearic acid on macrophage differentiation and Mycobacterium tuberculosis control. Cell Immunol 2016; 303: 24-33.

\begin{abstract}
The diagnosis of tuberculosis has been based on the direct detection of mycobacteria. However, it is estimated that only can be achieved in $10 \%$ of the cases and it is necessary to combine with confirmatory methods such as culture that may take several weeks to growth been evident. Methods based on sequence amplification of nucleic acids show high sensitivity and specificity, but are not always accessible to all laboratories due to infrastructure requirements and the cost of inputs. The limitations for the diagnosis induce to a continued research for mycobacterial metabolites by different approaches that are later easy to trace in very basic laboratory conditions. This review includes some of the methodological approaches based on mycobacterial derivatives and their value as a tool to detect the mycobacteria.
\end{abstract}

Key words: Tuberculosis, lipids, lipoarabinomannan, trehalose dimycolate, chromatography. 


\section{$\bar{N}$ Laborathrio ${ }^{\circledR}$ Clínico U Hematológico}

Creemos en los sueños de todos los colombianos que llevan en la sangre confianza

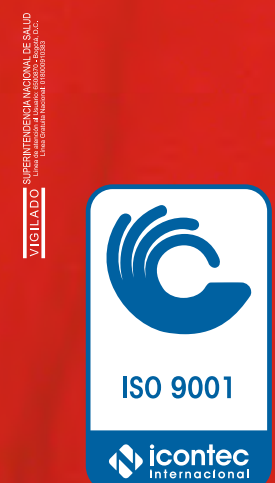

4 icontec

Sede Principal Poblado: Carrera 43C No. 5-33

Toma de Muestras: Centro Comercial Sandiego, Torre Norte, Piso 10, No. 1034

Teléfono: 4444200 - www.lch.co - Medellín 